\title{
How Content Authored by People with Dementia Affects Attitudes towards Dementia
}

\author{
AMANDA LAZAR, University of Maryland, United States \\ ROBIN N. BREWER, University of Michigan, United States \\ HERNISA KACORRI, University of Maryland, United States \\ JONGGI HONG, University of Maryland, United States \\ MARY NICOLE DUGAY PUNZALAN, University of Maryland, United States \\ MAISARAH MAHATHIR, University of Michigan, United States \\ OLIVIA VANDER HYDE, University of Michigan, United States \\ WARREN ROSS III, University of Maryland, United States
}

\begin{abstract}
Negative attitudes shape experiences with stigmatized conditions such as dementia, from affecting social relationships to influencing willingness to adopt technology. Consequently, attitudinal change has been identified as one lever to improve life for people with stigmatized conditions. Though recognized as a scaleable approach, social media has not been studied in terms of how it should best be designed or deployed to target attitudes and understanding of dementia. Through a mixed methods design with 123 undergraduate college students, we study the effect of being exposed to dementia-related media, including content produced by people with dementia. We selected undergraduate college students as the target of our intervention, as they represent the next generation that will work and interact with individuals with dementia. Our analysis describes changes over the period of two weeks in attitudes and understanding of the condition. The shifts in understanding of dementia that we found in our qualitative analysis were not captured by the instrument we selected to assess understanding of dementia. While small improvements in positive and overall attitudes were seen across all interventions and the control, we observe a different pattern with negative attitudes, where transcriptions of content produced by people with dementia significantly reduced negative attitudes. The discussion presents implications for supporting people with dementia as content producers, doing so in ways that best affect attitudes and understanding by drawing on research on cues and interactive media, and supporting students in changing their perspectives towards people with dementia.
\end{abstract}

\section{CCS Concepts: • Human-centered computing $\rightarrow$ Human computer interaction (HCI).}

Additional Key Words and Phrases: dementia, attitudes, activism, disability, education

\section{ACM Reference Format:}

Amanda Lazar, Robin N. Brewer, Hernisa Kacorri, Jonggi Hong, Mary Nicole Dugay Punzalan, Maisarah Mahathir, Olivia Vander Hyde, and Warren Ross III. 2021. How Content Authored by People with Dementia Affects Attitudes towards Dementia. Proc. ACM Hum.-Comput. Interact. 5, CSCW2, Article 398 (October 2021), 32 pages. https://doi.org/10.1145/3479542

Authors' addresses: Amanda Lazar, Lazar@umd.edu, University of Maryland, College Park, Maryland, United States; Robin N. Brewer, rnbrew@umich.edu, University of Michigan, Ann Arbor, Michigan, United States; Hernisa Kacorri hernisa@umd.edu, University of Maryland, United States; Jonggi Hong, jhong12@umd.edu, University of Maryland, United States; Mary Nicole Dugay Punzalan, mpunzala@terpmail.umd.edu, University of Maryland, United States; Maisarah Mahathir, maimich@umich.edu, University of Michigan, United States; Olivia Vander Hyde, oliviav@umich.edu, University of Michigan, United States; Warren Ross III, wlr3iii@umd.edu, University of Maryland, United States.

Permission to make digital or hard copies of all or part of this work for personal or classroom use is granted without fee provided that copies are not made or distributed for profit or commercial advantage and that copies bear this notice and the full citation on the first page. Copyrights for components of this work owned by others than the author(s) must be honored Abstracting with credit is permitted. To copy otherwise, or republish, to post on servers or to redistribute to lists, requires prior specific permission and/or a fee. Request permissions from permissions@acm.org.

(C) 2021 Copyright held by the owner/author(s). Publication rights licensed to ACM.

2573-0142/2021/10-ART398

https://doi.org/10.1145/3479542

Proc. ACM Hum.-Comput. Interact., Vol. 5, No. CSCW2, Article 398. Publication date: October 2021. 


\section{INTRODUCTION}

Researchers and practitioners are preparing the next generation of computer scientists, designers, and information scientists to understand diverse disabilities and how to create accessible technologies [61]. Researchers are sharing best practices and curricula [12, 75, 90], studying experiences and attitudes towards teaching accessibility [48, 50, 89, 90, 97], and assessing the impact of this curricula on students $[50,64]$. While targeting knowledge is necessary, it may not be sufficient. Societal attitudes towards disability can mean that, even with complete knowledge on how to do so, designers may still not make technology accessible [42]. Societal factors also affect how people with disabilities use technology: even when assistive technologies are functionally useful, they may be rejected because of stigma [98]. Just as attitudes towards and understanding of disabilities are key to technologists, there are myriad other kinds of practitioners who contribute to the physical and social world in which people with disabilities live.

In the case of dementia, an umbrella term for conditions such as Alzheimer's disease that progressively affect cognitive functioning, architects, social service providers, health care workers, and theater and restaurant workers are just a few examples of professionals who shape the opportunities available to people with dementia. In part, this is due to the ways that the social environment and attitudes of others play a major role in the experience of living with progressive cognitive impairment. Kitwood, a prominent figure in contemporary dementia care approaches, noted how the social environment defines what opportunities are available to individuals with dementia [56] For example, a social partner may treat a person with dementia like a child, which means that this individual will only have opportunities for childlike activities and conversation [56]. Another example is the way that a dementia diagnosis is typically seen as implying the end of any occupations or responsibilities [102]. This view links directly to an esteem hypercognitive societies place on cognition and rationality, with dementia thus signalling the inability to be a functioning member of society [88]. As a result, there is not an emphasis on creating the resources to support people with dementia in living well with their condition [102]. These views influence and limit the ways that technologies are envisioned [24].

The World Health Organization describes an "urgent need" for improving awareness and understanding of dementia, "across all levels of society" [84]. One segment of society that has received special emphasis in past work seeking to improve awareness and understanding of dementia are college students $[38,39,71]$, and individuals studying to become health care professionals in particular [17, 33, 52, 53, 72, 73]. Students (including but extending beyond computer scientists, engineers, designers, informaticists and information professionals) are an important population to target for attitudinal change and improvement in their understanding of dementia given that they are preparing for a variety of careers and opportunities where they may interact with this population.

There are two gaps left open in prior with work with students that our study seeks to address. First, past work largely falls into two areas of intervention: either fostering contact between students and people with dementia (e.g., in choirs [38]), or with educational materials about (but not involving the input of) people with dementia (e.g., [73]). To our knowledge, interventions have not used content that includes what people with dementia themselves think is important knowledge for those without this condition. A second gap that our work addresses is that while increased exposure to people with with dementia is a promising way forward, a review of past work asserts that there is a need for research to test how exposure may work "at scale," via social media and other mass delivery platforms [41].

We present a study with a mixed methods design to address the following research questions: 
RQ1: How does media format (audio vs. text) and content producer (someone with dementia vs. someone without dementia) affect understanding of dementia?

RQ2: How does media format (audio vs. text) and content producer (someone with dementia vs. someone without dementia) affect attitudes towards people with dementia?

To answer these research questions, we paired interviews with a randomized control experiment testing the following hypotheses, where understanding and attitudes (positive, negative, and overall) are based on instruments such as the Alzheimer's Disease Knowledge [13], Allophilia [86], Fabroni Ageism (modified to assess negative attitudes towards dementia) [31], and Dementia Attitudes [83] scales:

H1: There is a difference in understanding of dementia after exposure to media about dementia and it varies by media.

H2: There is a difference in positive attitudes towards dementia after exposure to media about dementia and it varies by media.

H3: There is a difference in overall attitudes towards dementia after exposure to media about dementia and it varies by media.

H4: There is a difference in negative attitudes towards dementia after exposure to media about dementia and it varies by media.

We recruited 123 undergraduate students. Students in the intervention condition were exposed to one of three types of content: new stories about dementia, audio recordings produced by people with dementia, and transcriptions of these audio recordings produced by people with dementia. We compare scores on instruments that assess understanding and attitudes before and two weeks after students interacted with the content on dementia and include a control group as a baseline. Though students described shifts in understanding of dementia in our qualitative analysis, such changes were not captured by existing instruments used in our quantitative analysis. More importantly, we find significant changes in negative attitudes towards dementia for one media condition, where students who read transcribed content from people with dementia had less negative attitudes after the intervention. Positive and overall attitudes towards dementia improved across each condition, including the control group. We supplement these quantitative data with a qualitative analysis of interview data. This analysis describes students' past experiences with the topic of dementia, where they revealed little exposure to lived experiences with dementia, as well as the perceptions that they described as having changed with exposure to the media.

We seek to make two contributions to CSCW research with the present study. First, content produced by people discussing stigmatized experiences is frequently studied to identify priorities [1, 32 ], and is already seen as a lever for intervening in prevailing social attitudes, such as in studies of disability-related online advocacy [2,67] - however, little is known about how this content affects audiences. Our research contributes an empirical investigation of the effect of content generated by a stigmatized group, people with dementia, over a period of two weeks. Second, researchers are attending to the ways that negative attitudes and misconceptions play a major role in the experience of aging and dementia, and scoping the ways that $\mathrm{CSCW}$ and HCI research can intervene $[25,62,107]$. We contribute a discussion that speaks to addressing negative societal perceptions towards dementia and ultimately, to combat discrimination toward this population.

\section{RELATED WORK}

\subsection{Changing Attitudes towards Disability}

Researchers are noting the need to not only educate individuals on ways to make technologies accessible, but also to target the social context, including overcoming stigma and combating social exclusion [42]. Shinohara et al's concept of social accessibility provides one lens on the interaction 
between social worlds and accessibility: socially uncomfortable situations can arise due to stigma and misconceptions about assistive technology in ways that lead to negative feelings and limit individuals' ability to present themselves to others in preferred ways [98].

HCI researchers have examined the work of individuals with disabilities working to change attitudes. For example, researchers have studied the online work of disability activists in the Hands Off My ADA initiative [2]. Li et al. further show how people with disabilities used offline, hybrid, and online forms of activism to participate in more accessible forms of protests and social movements [67].

As researchers study these movements and strive to change attitudes towards disability, it is key to note that content produced to change opinions of disability do not always have the intended effect. For example, the often utilized notion of empathy can "other" people with disabilities [7], and disability simulations can undermine efforts to increase comfort with the topic of disability [80] While digital content produced by people with disabilities has not been studied in terms of its effects on the people who view it, a study of political hashtags has found that hashtags can counteract the intentions of posters, such as resulting in the audience seeing the topic as less socially important [92]. This work indicates that there is a need to understand the effects of content produced by people with stigmatized conditions to influence attitudes, and to understand optimal modes of delivery to avoid unintended consequences.

\subsection{Dementia and Stigma}

Stigma related to disability, age, race, and other human characteristics is reproduced and reified through technology. CSCW researchers are studying how negative and discriminatory attitudes are perpetuated across a variety of platforms, technologies, and interaction techniques, from avatars [37] to search engines [49].

In dementia, stigma acts as a barrier to care and support [41] and can lead people with dementia to avoid potentially useful technologies [26]. Dementia is a highly stigmatized condition $[5,6,36]$. Conceptualizations of dementia are often centered around the idea that changing cognitive abilities in dementia equate to losing one's "self" [4-6, 36, 57]. Researchers have studied attitudes towards dementia across the world, often finding negative attitudes towards this condition [19, 43, 87].

Recognizing the urgent need to counteract negative attitudes [84], researchers have tested a number of approaches to reduce stigma and negative attitudes. Some focus on increasing contact between people with and without dementia, such as attending museum programs together [93] or participating in an intergenerational choirs [38]. Others expose people to second hand information about dementia, such as educational materials [72] which may include fictional vignettes to depict biographies of people with dementia $[15,116]$. A third approach strives to provide a view of what it feels like to live with dementia [22, 34, 53, 95], for example through a first-person virtual reality program [53, 95]. Often, the target of these interventions are college students [29, 38, 39, 71, 121], in particular individuals studying to become health care professionals [17, 22, 33, 47, 52, 53, 72, 73] The goal with intervening during the training of students in health fields is twofold. The first is to build interest in working with people with dementia, as there is a shortage of people equipped to and interested in working with this population $[17,71]$. The second is to ensure that once students are practicing, they provide better and more humanistic care $[33,52]$. Though most of these studies take place in healthcare and education-oriented disciplines, Foley et al studied the experiences of undergraduate students co-designing with people with dementia, finding qualitative evidence that resonates with our data. For example, students shifted towards normalizing the experiences of people with dementia, recognized the variability of what it means to live with this condition, and developed understandings that differed from that they had learned in their classes [29]. 
With a move towards "dementia-friendly communities" across the globe, there is a need to reduce stigma and improve understanding for people of all ages [46]. As such, all members of a community should develop a basic familiarity and comfort such that people with dementia can be included in daily life. Rather than solely targeting health care professionals for attitudinal change, a shift towards dementia-friendly communities implies that anyone should be prepared to interact with people with dementia. Given that undergraduate students in a variety of fields will go on to work in settings where they may encounter people with dementia, our study targets students in a variety of disciplines.

\subsection{Communications and Media Studies Theories on Cues}

In this study, we examine how audio and text-based media produced by people with dementia affect dementia-related attitudes and understanding. Past research has studied the ways that different forms of media provide different cues that have a range of effects on the listener. For example, recall [23] and trust change $[21,69,120]$ when information is presented via different mediums and modalities. Some past work suggests that audio may be particularly powerful in supporting processing [100] and trust [117].

Communication researchers have studied the role of cues on attitudes, though there is no consensus on how they mediate attitude change. Theories that focus on "richness" of cues describe how communication mediums vary based on the richness of how information can be communicated. Richness is based on factors such as "number of cues, immediacy of feedback, use of natural language, and customization" [112]. Based on this prior work, reduced nonverbal cues in written media may make it difficult to understand others' personality characteristics, which are central to persuasion and attitude change [112].

Other theories have pushed back on the idea that richness of media affects an unchanging listener. Some theories specify how media that lack visible cues about a person (e.g. facial features, gestures) leads people to make guesses about who generated the content [111] because there is a lack of 'presence,' and that people adapt to missing cues [112]. Other theories suggest people rely on nonverbal cues in the media [111] (e.g., emoticons/emojis, punctuation, capitalization) or systemgenerated cues [105] (e.g. likes) instead of cues from their own environments and experiences to form impressions. And, individual factors can impact the effects that cues may have on attitudes. For example, prior experience or knowledge with a subject area can mitigate the effects cues may have on attitude change [79]. Further, context matters. Heim et al. provides evidence that refutes theories of media richness, finding that media effectiveness and preference are task-dependent [40].

More recent research has discussed differences in non-verbal and verbal cues, often in the context of conversational agents. For example, non-verbal cues used with chatbots can be perceived as human-like or having more of a "conversational human voice" when compared to informal speech displayed through text [68]. Yet, a range of verbal social cues like choices of words, voice gender, or vocal pitch can each affect perceptions of the content. Feine et al. (2019) provide a taxonomy of "verbal, visual, auditory, and invisible" cues informed by prior literature [27]. In this paper, we investigate the role of cue modalities - text-based and audio-based - across three stimuli. The research community presents mixed findings about the role of audio cues [101]. While audio cues can be perceived as more credible, persuasive, and trustworthy because of fewer opportunities for misinterpretation than could occur by text, there has been other work that shows college-aged students respond better to text campaigns, adapting to computer-mediated communication norms in online communities $[21,101]$. In our work, we similarly find a text-based condition as more effective than an audio condition for changing students' negative attitudes. 


\section{METHODS}

Motivated by prior work calling for multimedia interventions exposing people to dementia [35] and to test attitudinal change at scale [41], we designed an experiment to evaluate the effects of different types of dementia-related media exposure ${ }^{1}$. We involved undergraduate students from two large public universities in the United States: site 1 is located on the East Coast, and site 2 in the Midwest. Our user study employs embedded design, a mixed methods design where qualitative data are collected within the primary quantitative design. Qualitative data was gathered through interviews with open-ended questions to further interpret results of a randomized control experiment. Participants are assigned to one of four groups:

Control: no exposure to stimuli.

News Articles: stimuli that include news stories about dementia.

Text Diaries: stimuli that include transcriptions of audio recordings produced by people with dementia.

Audio Diaries: stimuli that include the audio recordings produced by people with dementia

Participants respond to four scales in pretest/posttest sessions that were set two weeks apart. Questionnaires were designed to assess attitudes and understanding of dementia and were adopted from existing instruments. The time period is informed by prior work which finds two weeks after initial exposure as a typical period for studies testing framing effects [66] and views changes at this point as "lasting over time" [65].Our experiment follows a mixed factorial design, where the pretest/postest contrast is treated as a within-subject factor and the groups as a between-subjects factor. Sample size was estimated using power-analysis (for a medium size effect $(f=0.25)$, power = 0.80 , alpha $=0.05$ ) indicating the need for 180 participants. However, with COVID-19 imposing research restrictions, our data collection was interrupted after we had collected data from 139 participants (as shown in Section 3.4, data from 123 students passed the quality control measures such as attention checks and are included in our analysis). We decided to conclude the study rather than resume it after COVID-19 research restrictions are lifted, as, given the early focus of media and government messaging on threats of COVID-19 for older adults [104], student perceptions of dementia and aging may have undergone drastic changes as a result of the pandemic. We understand that being underpowered can affect our ability to observe significant differences; we account for this by also reporting any trends in our data through descriptive statistics.

All procedures were approved by our University Institutional Review Boards. All participants consented before study procedures began. In order to avoid an inappropriate power dynamic or coercion, we did not recruit undergraduate students from our own courses or research groups. Further, undergraduate or graduate researchers ran all sessions.

\subsection{Stimuli}

We selected Dementia Diaries (https://dementiadiaries.org/) as a source of dementia-related content for this study. Dementia Diaries is a project that supports the creation and sharing of audio recordings by people with dementia. Past research has found that the Dementia Diaries project provides a safe place for people with dementia to share their authentic experiences and priorities [62]. Given the work and relationship building that goes into creating this supportive platform [62], we chose to use existing media from the Dementia Diaries project rather than attempting to create our own content with people with dementia. This means that we had some constraints in using the kinds of media that were supported by this project - we could not use video as a condition in this study, even though video has an increased richness of cues that may affect attitudes ${ }^{2}$. However, given

\footnotetext{
${ }^{1}$ Supplementary material including datasets can be found at https://iamlabumd.github.io/DementiaAttitude/.

${ }^{2}$ The Dementia Diaries project has since begun to encourage and include videos.
} 

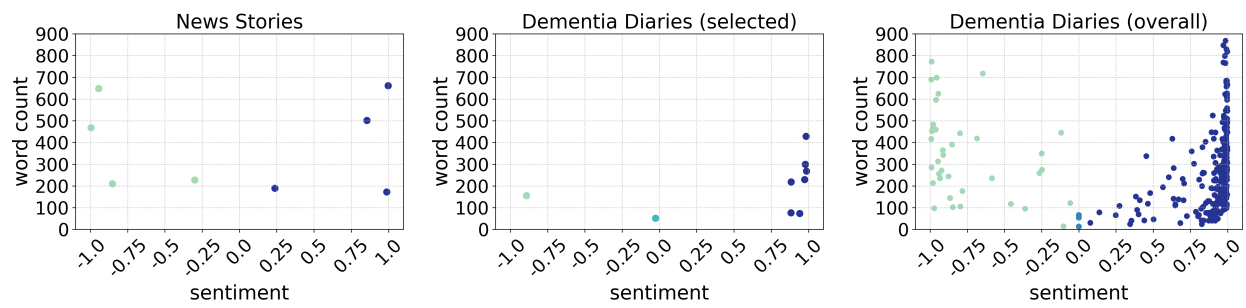

Fig. 1. Word count and sentiment scores of News Stories (left) and Dementia Diaries (middle) that serve as stimuli in our study, with news being balanced and diaries being representative of overall available (right). Sentiment scores, also color-coded, fall in four bins: negative [ $1,-0.05]$, negative neutral $(0.05,0)$, positive neutral $[0,0.05)$, and positive $[0.05,1]$.

that Dementia Diaries does include audio recordings, by creating transcripts of those recordings we could evaluate our results in light of other research, such as past work on the impact of voice cues on attitudinal change [112]. Further, audio is a meaningful condition to evaluate given that voice cues can also relate to dementia specifically (e.g., pausing in speech associated with the condition [99]).

Dementia Diaries was started by a non-profit journalism agency as a way to support people with dementia to share their stories online. Later, it was handed over to Innovations in Dementia which is a UK organization focused on the rights and needs of people with dementia. The goal of the project is now framed as sharing the "real and raw" voices of people with dementia in order to influence attitudes and understanding. The platform lets people with dementia record and share audio recordings on their website, with links to recordings also regularly posted on social media platforms such as Twitter. The project relies on volunteers to transcribe recordings that are then posted alongside the audio recordings.

We transcribed 16 audio recordings (the project indicates recordings that need transcription) and selected 9 of these to present as stimuli and scraped the corresponding audio recordings with permission from Dementia Diaries. The selected stories ended up spanning from October 2016 to January 2018. The word count and sentiment ${ }^{3}$ of these stories is illustrated in Figure 1 (middle). As shown Figure 1 (right), these stories are representative of a larger pool of consisting of all 201 available dementia diaries. Each participant in these conditions viewed text for or listened to all 9 stories. The supplementary material includes links to each file hosted on Dementia Diaries (though participants were exposed to the stimuli on our own study portal).

To more reliably measure the effect that content generated by people with dementia may have on participants' attitudes, we employ two control conditions: no stimuli and stimuli from media content that is typically available about dementia; we chose news stories given that they may be consumed in similar ways to the Dementia Diaries (i.e., versus hours-long movies).

To gather News Stories on dementia, we used Nexis Uni ${ }^{4}$. We searched for articles that had been published over the period of one year (February 2017-February 21st, 2018) using the search term "dementia" OR "Alzheimer's Disease". This resulted in 710 stories. We observed that the stories we retrieved from Nexis Uni with the default search were largely positive stories, as indicated by

\footnotetext{
${ }^{3}$ As a proxy for emotional valence, we ran a sentiment analysis in Python using VADER Sentiment Analysis https://github. com/cjhutto/VaderSentiment.

${ }^{4}$ https://www.lexisnexis.com/en-us/products/nexis-uni.page
} 
sentiment analysis ${ }^{5}$. Since this condition serves as a baseline, we wanted to balance the content across articles with positive and negative sentiment. Therefore, we ran another search with the Lexus filter set to "negative news," which yielded an additional 290 stories. We selected 8 stories so that they matched the word length characteristics of the overall content produced by people with dementia on Dementia Diaries, and balanced positive and negative sentiment, as shown in Figure 1 (left). To do so, we first sought to understand the range of Dementia Diaries transcript lengths. We set the maximum length of transcripts to 800 words, with short defined as $<=266$ words, medium as 266-533 words, and long as 533-800 words. The sentiment analysis, similarly to the dementia diaries, can be ranked (based on the exact word) from -4 to 4 ( -4 being extremely negative to 4 being extremely positive). Stories were split into the following bins: positive stories had a compound score $>=0.05$, positive neutral being between 0 and .05 , negative neutral being between -0.05 and 0 , and negative stories as having a compound score of $<=-0.05$. We randomly selected news stories that fit each of these bins.

\subsection{Instruments}

We selected four scales to assess attitudes and understanding of dementia. For consistency, in each of the scales, we used "people with dementia" to refer to the group for which attitudes or understandings are measured (we note where this is a departure from the scale's wording below). We placed four attention checks in the survey (i.e., "For this question, please select "Strongly Agree").

The Alzheimer's Disease Knowledge Scale: a 30-item True/False instrument that measures understanding of dementia [13]. The scale covers "risk factors, assessment and diagnosis, symptoms, course, life impact, caregiving, and treatment and management" and was designed for use with students, healthcare professionals, and the general public [13]. We replaced the term "Alzheimer's Disease" wherever it appeared with the term "dementia".

Allophilia Scale: A 17-item 6 point Likert scale instrument which measures positive attitudes towards outgroups [86]. This scale measures factors including affection, comfort, kinship, engagement, and enthusiasm [86]. This scale has been used for a variety of characteristics, including age [108], race [58], and religion [60]. The scale has been validated for use with college students to evaluate positive attitudes towards dementia $[54]^{6}$.

Fabroni Ageism Scale: A 29-item Likert scale instrument that measures the affective component of ageism (negative attitudes and prejudice based on age) towards older adults [31]. We followed the direction of a project that replaced the term "old people" with the term "dementia" and used a 5-point scale to measure negative attitudes towards dementia. One original question asks if a participant would prefer not to go to an open house at a senior's club if they were invited: we replaced this term with "a club for people with dementia".

The Dementia Attitudes scale: A 20 -item 7 point Likert scale instrument that measures attitudes through dementia knowledge and social comfort [83]. This scale was created and tested with college students [83]. The term in this scale is ADRD (Alzheimer's Disease and Related Dementias), which we replaced with "dementia".

\subsection{Procedure}

Below, we describe study procedures. Participants were screened remotely through an online Qualtrics survey. So that we could encourage attention focused solely on study materials, we had

\footnotetext{
${ }_{5}^{5}$ Objective scores from VADER Sentiment Analysis were confirmed with subjective researchers' opinions.

${ }^{6}$ The authors remove a question with a lower weight than others, which we retained: "I would like to be more like people with dementia".
} 
students come in to our labs on campus and use a research laptop to engage in sessions 1 and 2. Each session was individual, with one student participating at a time. Research assistants guided participants through the procedures described in each session.

3.3.1 Prior to Session 1. All participants were screened prior to session 1. We gathered demographics related to age and whether the individual was an undergraduate student at the respective university, which were used to screen out individuals who did not meet the inclusion criteria (18 and over and a student at our universities). Additional demographics that we gathered included year at university, major, gender, racial/ethnic background, and parent's education. We then provided a definition of dementia before asking about their experience, which was "Dementia is often defined as a decline in memory or other thinking skills severe enough to reduce a person's ability to perform everyday activities. Dementia includes Alzheimer's disease (the most common cause of dementia) as well as vascular dementia, dementia with Lewy bodies, and Parkinson's disease dementia." The last two questions asked "Do you have any personal experience interacting with family members or friends who have dementia?" and "Do you have any volunteer or work experience where you interacted with older people with dementia (e.g. at nursing homes, hospitals or inter-generational programs)." After participants were screened, the research assistant randomly assigned ${ }^{7}$ the participants in one of the four conditions while blocking for prior experience with dementia. We did a random assignment rather than blocking process for Site 2 given the smaller scale of recruiting at this site.

3.3.2 Session 1. In session 1, participants filled out the four scales we selected for this study. Afterwards, participants were exposed to media about dementia in the form of transcripts, audio recordings, or news articles; or, if in the fourth control condition, they were not exposed to any media. All participants were exposed to the media in the same order. These sessions took about 20 minutes.

3.3.3 Session 2. Two weeks after session 1 was conducted, participants returned for the second session, scheduled for 40 minutes. Participants retook the scales they filled out during session 1.

After individuals finished filling out the scales, they were interviewed by the researcher about their thoughts on dementia, as well as on the media that they were exposed to. We also showed participants the forms of media that they had not seen in their condition (i.e., someone in the News condition would be shown Text and Audio Diaries during the interview), and asked about their perceptions of this content. We showed all participants all conditions at the interview so that we could have a richer discussion that involved comparisons between the different forms of stimuli. This exposure did not affect their scores on the scales as they had already taken them when they got to the interview.

In the interview, a subset of questions were added such as, "Can you tell me about the person you think might have created this?", and "Would it be beneficial for understandings of dementia to change?". These questions were less central to the analysis and were not necessary to add for site 2 . One additional difference was that participants in the control condition at site 2 did not encounter any form of media during the interview.

After completing the second session, participants received 20 dollars or course credit as compensation.

\subsection{Participants}

Data was collected over the period of approximately one year: from early March 2019 to early March 2020. During this period, a total of 139 individuals took part in this study - as described

\footnotetext{
${ }^{7}$ An R script is used to generate random assignments.
} 
below, data from 123 of these participants passed our quality control measures. To strengthen the generalizability of our findings, participants came from two United States universities, with Site 1 in the Eastern region of the US (93) and Site 2 in the Midwestern region (46). We continuously recruited over the duration of the study through paper flyers, listservs, and class announcements in-person or over email. Recruitment materials did not mention dementia, as we did not want to only draw a sample who were interested in this topic: instead, the topic was framed as understanding how technology affects understandings of health conditions.

Data from 16 participants were removed: 2 did not show up for the second session ${ }^{8} ; 2$ exceeded the time limit of two weeks between sessions; 2 provided invalid data; and 10 had incomplete data due to researchers' error'.

We have a relative balanced ratio on past experience with dementia (none:some) across the four groups: Control (13:19), News Articles (15:12), Text Diaries (18:15), and Audio Diaries (17:14). We observe a nearly balanced age distribution: Control $(\mu=19.88, \sigma=1.54)$, News Articles $(\mu=19.85$, $\sigma=1.56)$, Text Diaries $(\mu=19.88, \sigma=1.92)$, and Audio Diaries $(\mu=19.52, \sigma=1.03)$. We observe a bit more than half of the participants identifying as female (66) compared to male (57) ${ }^{10}$ though not always as pronounced across most groups: Control (17:15), News Articles (13:14), Text Diaries (20:13), and Audio Diaries (16:15).

We observe diversity in participants' disclosed racial/ethnic background with participants identifying as Black or African American (3:5:3:4) ${ }^{11}$, East Asian (9:2:4:6), Hispanic or Latino (4:0:3:2), Native Hawaiian or Other Pacific Islander (0:0:0:1), South Asian (5:10:4:6), White (9:9:11:8), or 'Some other race' (2:1:8:4). The majority of the participants disclosed being born in the United States (25:21:22:25) compared to other countries (7:6:11:6) including Australia, Bangladesh, Brazil, China, Ethiopia, Guyana, India, Indonesia, Israel and the Occupied Territories, Republic of Korea, Malaysia, Togo, Trinidad \& Tobago, and Turkey.

All participants are undergraduate students with Site 2 having a larger pool of freshmen students. However, the distribution across the four treatments was roughly balanced in each site and overall. The majority of participants reported majoring in Information Science (11:12:12:10) or another STEM field (7:6:6:10). Few were in the Languages $(0: 2: 2: 1)$, double major $(3: 2: 1: 2)$, or undecided $(3: 2: 1: 1)$.

The majority of participants had parents or legal guardians that graduated from college (8:9:8:10) or attended some graduate school (14:14:19:19). Few had parents or legal guardians that completed an associate degree (2:0:1:0), attended some college (4:2:2:1), completed High School (1:2:2:0), did not complete High School (2:0:1:1). Only one participant reported not knowing (1:0:0:0).

\subsection{Quantitative Analysis}

We test four hypotheses either through a Two-Way Mixed Model ANOVA or a non-parametric alternative such as Align Rank Transform [119] based on Shapiro-Wilk normality test. We employ attention checks within each instrument; data from those who failed the attention check are excluded for the analysis of responses within that instrument - we report these numbers in the findings section. For those who pass the attention checks, we convert all Likert-scale responses to numeric-based Likert data ranging from 1 to $5,6,7$, respectively.

H1. Using Align Rank Transform, we examine whether there is a difference in the number of correct Alzheimer's Disease Knowledge answers between Session 1 and 2; whether there is a

\footnotetext{
${ }^{8}$ Both were unresponsive to emails.

${ }^{9}$ Qualtrics did not save participants' data

${ }^{10}$ We included other options for reporting gender in the survey.

${ }^{11}$ Distribution across groups in the following order: Control, News Articles, Text Diaries, and Audio Diaries
} 
difference between the Control, News Articles, Text Diaries, and Audio Diaries groups; and if the effect between Sessions differs across groups (a.k.a. there is an interaction effect).

H2. Using Align Rank Transform, we examine whether there is a difference on the average Allophilia[86] scores between Session 1 and 2; if there is a difference between the groups; and if the effect between Sessions differs across groups.

H3. Using Align Rank Transform, we examine whether there is a difference on the average Fabroni Ageism [31] scores between Session 1 and 2; if there is a difference between the groups; and if the effect between Sessions differs across groups.

H4. Using a Two-Way Mixed Model ANOVA, we examine whether there is a difference on the average Dementia Attitudes [83] scores between Session 1 and 2; if there is a difference between the groups; and if the effect between Sessions differs across groups.

When the results of ANOVA or Align Rank Transform show a significant main effect of the media type or interaction effect, pairwise comparisons are conducted using Mann-Whitney U tests or Wilcoxon signed rank tests, respectively. For all tests our significance level was $\alpha=.05$ with Bonferroni correction, where applicable.

\subsection{Qualitative Analysis}

Unlike the quantitative analysis process, we did not begin qualitative analysis with any specific research questions, but rather inductively analyzed students' answers to the interview questions (though the larger research questions of the project, described in the introduction, informed the interview questions themselves). Our analysis followed a thematic analysis approach [9]. The steps we took are described in detail below.

All audio files were transcribed. We did not include false starts ("I mean - I thought - I wanted") unless it contributed meaning, and removed filler words (e.g., pervasive "like"s or "you know"s).

Three research assistants familiarized themselves with the data through a mix of conducting, transcribing interviews, and reviewing interviews. Next, they open coded 19 transcripts. At this stage, the codes from site 1 and site 2 were kept separate. A research assistant from site 1 created initial groupings of similar codes into higher level themes based on the Site 1 data (six transcripts). Initial codes included "News articles can promote awareness," "unaware of risk factors", and "interesting because people sounded 'normal', with early themes including "audio vs text" and "What society thinks people with dementia go through". The research assistants at site 2 sorted their codes into site 1's preliminary codebook, noting codes that did not fit into the existing structure. As a team, we refined the codebook, including creating new themes where the site 2 data did not fit into the existing structure, and reorganizing the codebook to ensure similar codes were grouped.

Two research assistants then used the initial codebook to code three additional transcripts (a focused coding approach). The research assistant coded the transcripts independently, and we repeatedly came back together as a team to discuss discrepencies between the ways the two transcripts were coded and ensure the team agreed with the ways codes were being applied. During this stage, we iteratively refined the preliminary codebook. Refinements included adding example quotations for each code, descriptions for codes that were unclear (e.g., education versus awareness), and removing redundant codes. We also made a major structural change to the codebook. Initially, reactions to a particular article would be kept separate from broader reflections on what had been learned in the study. We realized that it was difficult to determine whether individuals were responding to a particular article or diary or the body of content that they had seen, so we stopped separating those categories.

As we made changes to the codebook, we continually went back to the initial quotes from the first 19 transcripts that had informed the codes to ground these changes in the data. By the third transcript, and with refinements made to the codebook, the two coders reached alignment in terms 
of how to apply the codes. The research assistants then applied the codebook to all of the transcripts using Taguette, a collaborative coding platform.

Once we began outlining the narrative of the paper around the quantitative hypotheses and data, we brought in the majority of the qualitative themes where they related to the research questions and quantitative results. Some of the qualitative themes did not relate to research questions or findings, and they were not included in this paper - as an example, a theme that we analysed but excluded from this paper was "Place" (or where people expected to find information about dementia).

\subsection{Limitations}

Stimuli: In audio recordings, students were able to hear the UK accents of speakers, while the transcribed Dementia Diaries did not necessarily cue students to locations. This may have affected students in a number of way, including their ability to understand some of the stories.

Carry over effect: Given that our experiment includes multiple dependent variables (i.e. understanding and different attitude scales) there is a possibility of carryover effects; our approach is to measure them in the same order for all participants with understanding being first so that it cannot be affected by recognizing patterns in the attitudes questions.

\section{FINDINGS}

The aim of our analysis is twofold. First, we seek to understand past experiences with dementia, as this gives context for our findings and also helps identify potential levers for intervention to change attitudes. To this end, we first provide context on participants' experiences with dementia with descriptive statistics and interview data. The second goal of our work is to understand whether content produced by people with dementia might change understanding and attitudes towards the condition. To this end, remaining two sections discuss differences in understanding and attitudes towards dementia based on interventions and control groups.

\subsection{Past Experiences with and Understanding of Dementia}

Almost half (49\%) of participants had some past experience with dementia; relatively few (16\%) had experience interacting with people with dementia that were both family or friends and work-related connections.

In interviews, students rarely referred to work experience with people with dementia, but students did describe family experiences with dementia, usually with grandparents or great-grandparents $(\mathrm{n}=38)$. In most accounts, this was explicitly acknowledged as dementia. For some, such as S114, the presence of dementia was guessed at: "I'm pretty sure my grandfather has it but because of the language barrier I don't really interact with him." For others, the term dementia was used with uncertainty, and cognitive impairment associated with advanced age: "I have two great grandmas, they're both 93... I don't know if they have dementia per se, I don't think it's ever been diagnosed, but they're older and their memory is not like a 50 year old's or anything like that." [S27]).

While a small number of anecdotes spoke to frequent interactions with family members with dementia, there were many accounts where interaction was much more limited, such as not seeing grandparents with dementia often. Many of these personal experiences were framed neutrally or negatively, and described advanced cases of dementia. For example, S4 shared that, "My grandma passed away from Alzheimer's so I was kinda sad but it was also a long time ago." In some cases, students heard about their grandparents' dementia largely through their parents, and had limited personal exposure: indicating that parents may be acting as a moderator of their understanding of dementia. S19 shared that the place that they typically heard about dementia was, "from my mom or something because, my grandpa had dementia so just her bringing it up or, her researching

Proc. ACM Hum.-Comput. Interact., Vol. 5, No. CSCW2, Article 398. Publication date: October 2021. 
it because she's worried that she might get it if it's genetic or anything." Though family members, and grandparents in particular, were the most referred to as their source of past experience, some participants spoke of gaining experience through relationships with people who knew people with dementia (e.g., "My mom's best friend's father has dementia. I had heard about him and knew of him" [S116]).

4.1.1 Dementia Not Relevant to College Students. Many interventions to change attitudes towards dementia focus on students in higher education. However, in interviews, few students spoke of learning about dementia in school beyond brief exposure, usually in psychology or health-related classes. Some students had such minimal exposure to the concept of dementia that they said that they had had a hard time filling out the first set of scales. This confusion was not always resolved - at the interview, S87 referred to a movie featuring someone with schizophrenia as their main exposure to dementia after they had completed other study procedures.

Some students attributed the general lack of knowledge and understanding with their stage in life, status as a college student, and the makeup of the places that they frequented:

"... I think our surroundings prevents us from having it being talked about because we go to school here and it's not like all the students here have dementia. It's something that mostly older people [experience], and we're in a college town and there's not many older people" [S29].

Because of this, students would need to be intentional about learning more about the topic: "I think I'd have to seek it out if I were to look for something about dementia" [S6].

When discussing why the topic did not come up more, in addition to it lacking relevance due to their age, some students expressed that the topic was uncomfortable to talk about. They ascribed this discomfort to people avoiding talking about sad topics, such as dementia which does not have a cure and is associated with loss. S14 explained that, "it's a conversation that we don't like to have," and described the discomfort as linked to views about what makes us human (these views are discussed extensively in the critical dementia literature $[6,36,88]$ ):

"I think memories are what makes us who we are... for a lot of people they could think it's like losing themselves, and that's a very scary thought. And maybe it's because the way that it's portrayed in the media... And so it's not a conversation that they would enjoy having."

As in the above quote, media, and movies and television in particular, were described as points of exposure, often in limited or negative ways. S34 and others attributed this to a focus of media on younger populations: "I do think there's a general lack of awareness of issues that affect older people. I do think especially with media, it tends to focus more on problems of younger people." S18 mentioned, "if I watch Youtube videos or Netflix it's always young people that I see, not really older populations which usually have dementia", highlighting that college students may watch media that is aimed specifically at younger groups. S116 linked the lack of representation to a "picture perfect type of media" that neglects showing populations with different disabilities, though they clarified that this landscape may slowly be changing: "now there's more mental health shows out there and awareness, but other types of disabilities like dementia [have] still not really made it into the mainstream media..."

4.1.2 Primary Exposure to Medical Framings of Advanced Dementia. In addition to media, news was also brought up as a point of exposure - not necessarily via intentional search, but where "stuff will just pop up." [S85]. Though descriptions of what was learned from the news were often vague ("Umm, yeah I guess the news.. They talk about aging and like health stuff and all that. I can't really think of anything specific but I know they do."), some students did recall specific topics they 
had seen on the news in the past: how to care for people [S61], people with dementia getting lost [S103, S36], and movements to prevent head injuries for sports players [S25].

When discussing the kind of information they learned from classes and the media, some students relayed a focus on medical topics and a neglect of what it was like to actually live with dementia:

"when I heard about dementia it's in like class or a textbook and they don't always go as far to have an excerpt of someone, like what it's like living with this disorder. You just kind of learn about the book definition about what is going on biologically in their brain." [S17]

"Cause dementia is not really talked about much... anything I ever hear about it comes from people who don't have it or from medical professionals or TV documentaries and stuff like that, so I've never actually thought about the person or persons with dementia or Alzheimers' thoughts" [S72]

To summarize, though many students described a basic understanding of dementia, this knowledge was often limited or negative. There was little discussion of insights into the lived experiences with dementia.

\subsection{Pre-Post Differences in Understanding Across Interventions}

The findings in this section speak to RQ1: How does media format (audio vs. text) and content producer (someone with dementia vs. someone without dementia) affect understanding of dementia? Our hypothesis $\mathbf{H 1}$ was that there is a difference in understanding of dementia after exposure to media about dementia and it varies by media.

A total of 107 participants passed the attention checks in both sessions when answering questions related to negative attitude towards people with dementia (data from 16 participants that did not are excluded from this analysis). Participant distribution across the four groups was: Control (28), News Articles (22), Text Diaries (30), and Audio Diaries (27).

The results of the Two-Way Mixed ANOVA show that there was a significant main effect of media type $(\mathrm{F}(3,103)=4.50, \mathrm{p}=.005)$. Pairwise comparisons using the Wilcoxon rank sum test with Bonferroni correction indicate that participants in the Text Diaries group scored significantly higher than those in the Control $(\mathrm{p}<.001)$ and News Articles $(\mathrm{p}=.004)$ groups on dementia understanding. The main effect of session (pre-intervention vs. post-intervention) was not significant on understanding $(\mathrm{F}(1,103)=3.52, \mathrm{p}=.063)$. However, there was a significant interaction between media type and session $(\mathrm{F}(3,103)=2.94, \mathrm{p}=.037)$. Post hoc tests indicate that participants in the Text Diaries group scored significantly higher in session 1 (getting roughly 1 to 2 more questions right) than those in the Control $(\mathrm{p}=.001)$ and Audio Diaries $(\mathrm{p}=.046)$; though this is not the interaction we were hoping to see as it merely indicates that participants in one of the groups happened to have a slightly better understanding of dementia before coming to our study. In $\mathbf{H 1}$, we were expecting that those exposed to dementia-related media (all but those in Control) would leave our study with a better understanding; more so, if they were in the Dementia Diaries groups (either text or audio). However, when looking at understanding scores prior to (session 1) and after (session 2) the intervention, we do not observe a significant difference, as shown in Figure 2. We suspect that this is a limitation of instruments for capturing dementia understanding as they tend to be more oriented towards biomedical views rather lived experiences of people with dementia.

In interviews, students did reflect on new knowledge from both the news stories and the Dementia Diaries, contextual data which may not have been easily captured with a quantitative measurement.

4.2.1 Understanding Dementia Risk Factors and Sensory Symptoms from News Stories. Students primarily reflected on news stories discussing the association between alcohol and dementia, likely in part due to there being two articles on that topic in the stimuli. This might also have been due to

Proc. ACM Hum.-Comput. Interact., Vol. 5, No. CSCW2, Article 398. Publication date: October 2021. 


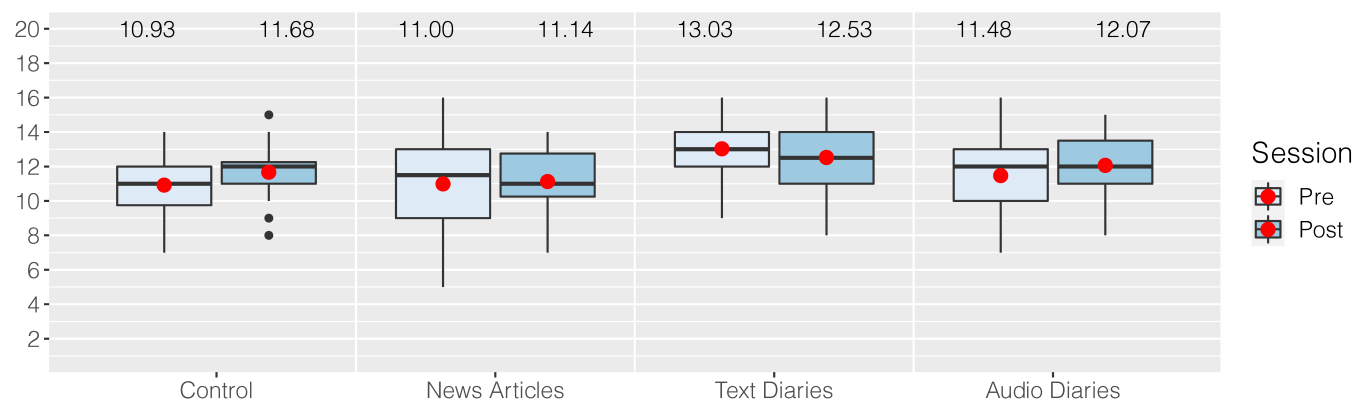

Fig. 2. Pre-post scores of understanding across intervention and control groups.

the relevance of the topic to their stage of life: S46 shared, "That one (news article) stood out a lot because college students drink a lot and they're not aware of the risks." For some, reading about the association between alcohol and dementia was linked to a new understanding that dementia was not only genetic, but also linked to lifestyle factors (i.e., alcohol intake).

Many students brought up sensory changes and hallucinations as symptoms that they had not known about before. That this was new information to them aligns with discourse on dementia that largely revolves around memory, with dementia activists [44] arguing for the importance of considering sensory changes more recently.

4.2.2 Learning about Diversity of Experiences with Dementia from Dementia Diaries. Students also spoke of new understandings that they gained from listening to and/or reading Dementia Diaries. First, students spoke of learning that dementia involves greater diversity than they had realized. This diversity existed in terms of the needs that varied from person to person:

"I think it's useful reading, and that you kinda see how people with dementia, how their lives are, and when people think dementia I think it gets grouped into one thing, but understanding that each person with dementia has their own case and their own specific needs...” [S39]

This diversity was located in the ways that people with dementia live with their condition: "different people have different responses to dementia... I mean some people look on it like an obstacle that they'll have to face while others will just feel like it's the end of their life and no hope" [S120]. S91 shared how this insight might translate into action: discussing the diaries that they had heard two weeks before, S91 shared that 'I feel like in terms of dementia it's very individualistic. So I wouldn't really know how to treat every single person that has dementia without having talked to them about how they're experiencing the world around them right now".

A second way that students reported their understanding of dementia changing in response to Dementia Diaries was in countering their initial view of dementia as largely at advanced stages, potentially linked to their experiences with older family members. S13 said that they were "very surprised", as "I totally associated [dementia] with people above the age of 80. Walking around in walkers and struggling to remember their own name... so this was a whole new perspective." This quote also refers to another understanding that students referenced, which was that some people developed dementia at younger ages (about 9\% of individuals with dementia are diagnosed as early onset, or onset before the age of 65 [84]). Some students may have left the study with an assumption that dementia did not involve advanced stages, such as S1 who shared "I thought people with dementia were very constrained, like they'd forget everything. Turns out, they're just slightly 


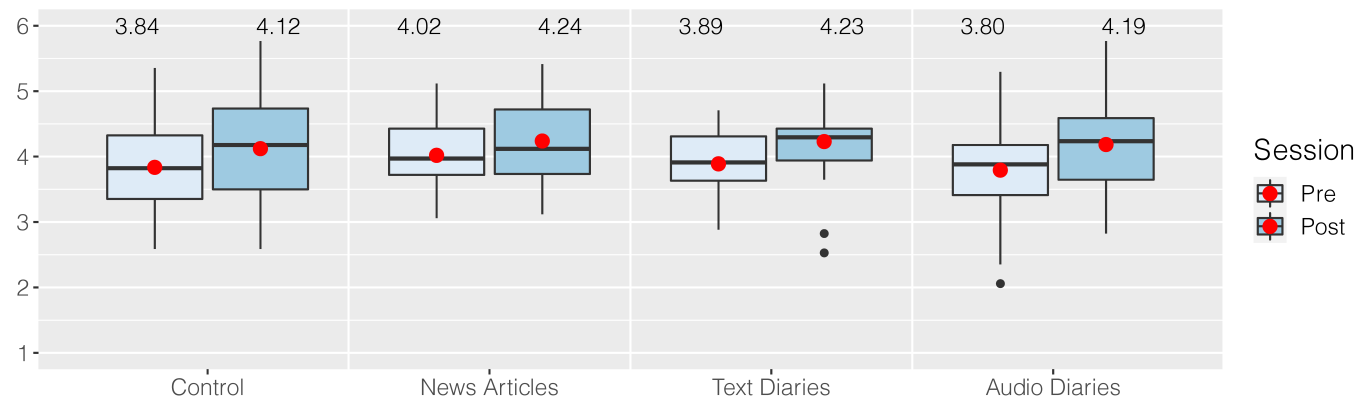

Fig. 3. Pre-post scores of positive attitude across interventions and control groups.

forgetful." [S1]. Others, though, were able to locate their past experiences in an understanding that dementia is a spectrum:

"Every time that I thought of dementia, it was very polar opposite thoughts. Like you either have it, or you don't have it. And if you have it, it's like "extreme." But I think just reading the text helped me realized that a lot people with dementia are in the "middle" of the spectrum and initially they can actually do a lot of things on their own... Because my experience with dementia was with my great grandfather and he was an "extreme" case. Well, I never got see anybody in the 'middle..' [S86]

\subsection{Pre-Post Differences in Attitudes Across Interventions}

While the prior section focused on changes in dementia-related understanding, the findings in this section speak to RQ 2: How does media format (audio vs. text) and content producer (someone with dementia vs. someone without dementia) affect attitudes towards people with dementia? We present quantitative results by testing hypotheses $\mathbf{H 2 - H 4}$ as well as qualitative findings related to attitudinal change.

4.3.1 H2: There is a difference in positive attitudes towards dementia after exposure to media about dementia and it varies by media. A total of 117 participants passed the attention checks in both sessions when answering questions related to positive attitudes towards people with dementia (data from 6 participants that did not are excluded from this analysis). Participant distribution across the four groups was: Control (31), News Articles (24), Text Diaries (32), and Audio Diaries (30) with scores shown in Figure 3.

The results of the Two-Way Mixed ANOVA show that there was no significant main effect of media type $(\mathrm{F}(3,113)=.27, \mathrm{p}=.845)$ on positive attitude. In contrast, there was a significant main effect of session $(\mathrm{F}(1,113)=37.32, \mathrm{p}<.001)$ on positive attitude, with an overall increase in scores from Session $1(\mu=3.90, \sigma=0.63)$ to Session $2(\mu=4.20, \sigma=0.67)$. The Wilcoxon test effect size $(\mathrm{r}=0.37)$ indicates a moderate effect. Given that the Control group was not exposed to any media about dementia, this result indicates that merely participating in the study (expressing understanding and attitudes towards dementia) can have an effect in one's positive attitude towards dementia We observe a tendency for these differences to be more noticeable in the Audio and Text groups compared to Control and News Articles, where stories could be more aligned with participants past experiences reflecting exposure to the medical model. In any case, we do not find a significant interaction between session and media type $(\mathrm{F}(3,113)=0.20, \mathrm{p}=.896)$, which could be due to our study being interrupted and underpowered.

The statements, where the difference between sessions is more prevalent, are: 
- I feel inspired by people with dementia.: There was an increase in all groups, except Control, with the largest shift in Text (S1: $\mu=3.59, \sigma=1.04$ to S2: $\mu=4.59, \sigma=0.95)$ and Audio (S1: $\mu=3.53$, $\sigma=1.44$ to $\mathrm{S} 2: \mu=4.13, \sigma=1.11$ ).

- I am impressed by people with dementia.: There was an increase in all groups again with the largest shift noticeable in Text (S1: $\mu=3.88, \sigma=1.34$ to S2: $\mu=4.53, \sigma=1.05)$ and Audio (S1: $\mu=3.70, \sigma=1.18$ to S2: $\mu=4.50, \sigma=0.94$ ).

- To enrich my life, I would try and make more friends who are people with dementia.: There was an increase in all groups again with the largest shift noticeable in Control (S1: $\mu=3.19, \sigma=1.25$ to S2: $\mu=3.81, \sigma=1.28$ ) and Audio (S1: $\mu=3.10, \sigma=1.12$ to $\mathrm{S} 2: \mu=3.80, \sigma=1.03$ ).

- I am comfortable when I hang out with people with dementia.: There was an increase in all groups again with the largest shift noticeable in Text (S1: $\mu=3.44, \sigma=0.84$ to S2: $\mu=4.16, \sigma=0.99$ ) and Audio (S1: $\mu=3.67, \sigma=0.96$ to S2: $\mu=4.20, \sigma=0.92$ ).

- I feel like I can be myself around people with dementia.: There was an increase in all groups again with the largest shift noticeable in Audio (S1: $\mu=3.80, \sigma=1.10$ to S2: $\mu=4.47, \sigma=0.73$ ).

- I would like to be more like people with dementia.: Although the overall response remains one of disagreeing, there is a shift towards softer responses such as 'slightly disagree' that is more prevalent for the News (S1: $\mu=2.33, \sigma=1.13$ to S2: $\mu=3.17, \sigma=1.31$ ) and Text (S1: $\mu=2.09$, $\sigma=0.96$ to $\mathrm{S} 2: \mu=3.00, \sigma=0.95)$ groups.

4.3.2 H3: There is a difference in overall attitudes towards dementia after exposure to media about dementia and it varies by media. A total of 115 participants passed the attention checks in both sessions when answering questions related to overall attitude towards people with dementia (data from 8 participants that did not are excluded from this analysis). Participant distribution across the four groups was: Control (31), News Articles (22), Text Diaries (32), and Audio Diaries (30) with scores shown in Figure 4.

The results of the Two-Way Mixed ANOVA show that there was no significant main effect of media type $(\mathrm{F}(3,111)=0.41, \mathrm{p}=.749)$ on overall attitude. However, there was a significant main effect of session $(\mathrm{F}(1,111)=8.32, \mathrm{p}=.005)$ on overall attitude, with an overall increase in scores from Session $1(\mu=4.90, \sigma=0.54)$ to Session $2(\mu=5.10, \sigma=0.54)$ regardless of intervention group assignment. The Wilcoxon test effect size $(\mathrm{r}=0.22)$ indicates a small effect. Similar to the positive attitude questions, this result indicates that participating in the study (expressing one's understanding and attitude towards dementia) can have an effect in one's overall attitude towards dementia. While we observe a tendency for these differences to be more noticeable in the Audio group and sometimes the opposite pattern for the Control group, we do not find a significant interaction between session and media type $(\mathrm{F}(3,113)=0.66, \mathrm{p}=.578)$. We suspect this is due to our study being interrupted and underpowered. Descriptive statistics show that the statements where the difference between sessions is more prevalent are:

- I admire the coping skills of people with dementia.: We observe a tendency for higher scores in all groups, except Control, with the largest noticeable difference in Audio (S1: $\mu=5.33, \sigma=1.24$ to S2: $\mu=5.93, \sigma=0.79$ ).

- We can do a lot now to improve the lives of people with dementia.: We observe an increase in all groups, except Control again, with the largest noticeable difference in Audio (S1: $\mu=5.23$, $\sigma=1.10$ to $22: \mu=5.93, \sigma=1.08$ ).

Though there were no significant results for the differences between text and audio conditions here, as described above, the audio condition does show larger changes for the most prevalent changes in scores on the statements about coping skills and ability to improve lives with dementia. 


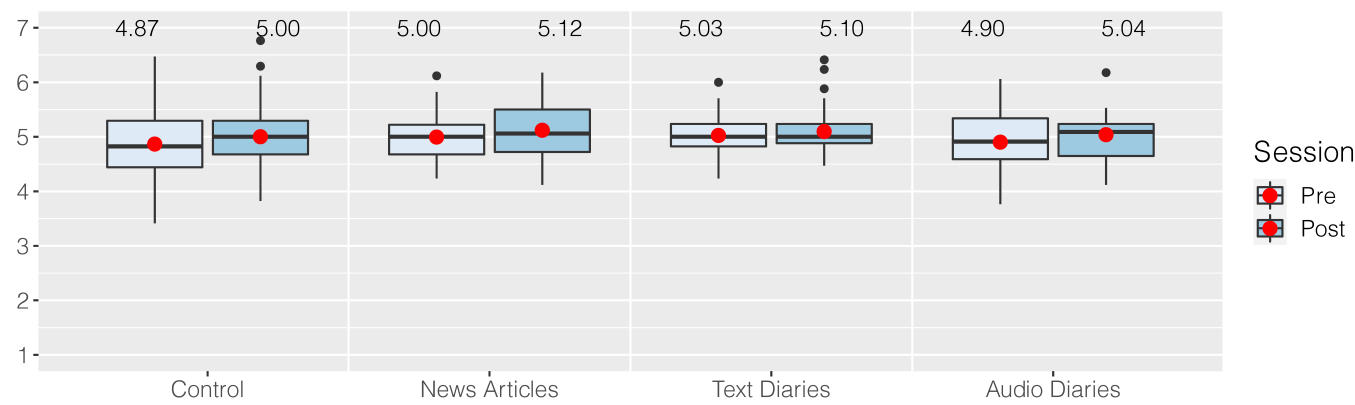

Fig. 4. Pre-post scores of overall attitude across interventions and control groups.

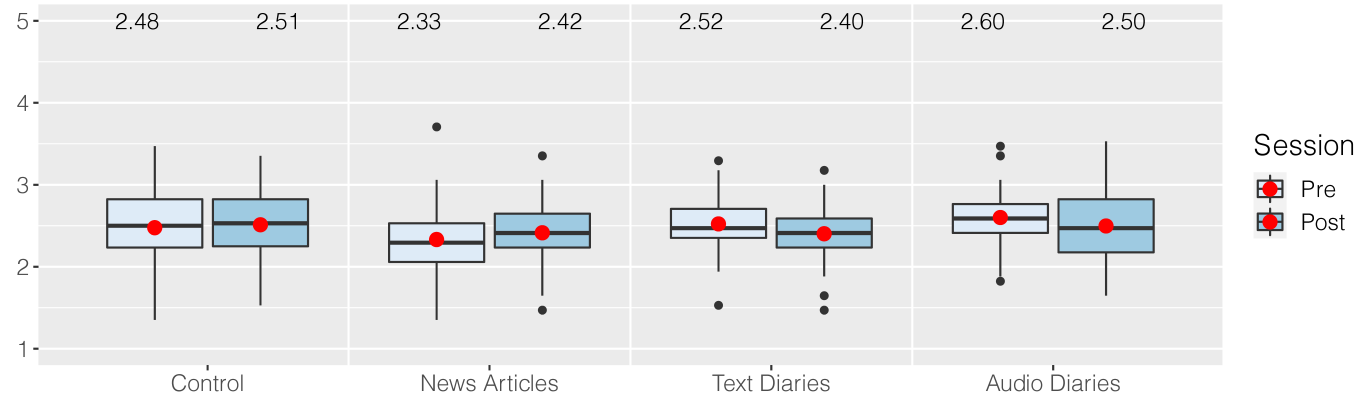

Fig. 5. Pre-post scores of negative attitude across interventions and control groups.

4.3.3 H4: There is a difference in negative attitudes towards dementia after exposure to media about dementia and it varies by media. A total of 117 participants passed the attention checks in both sessions when answering questions related to negative attitude towards people with dementia (data from 6 participants that did not are excluded from this analysis). Participant distribution across the four groups was: Control (29), News Articles (30), Text Diaries (25), and Audio Diaries (33) with scores shown in Figure 5.

The results of the Two-Way Mixed ANOVA show that there was no significant main effect of media type $(\mathrm{F}(3,113)=0.86, \mathrm{p}=.465)$ on negative attitudes. In addition, there was also no significant main effect of session on negative attitude $(\mathrm{F}(1,113)=0.86, \mathrm{p}=.357)$. In contrast, there was a significant interaction between media type and session $(\mathrm{F}(3,113)=3.07, \mathrm{p}=.031)$, and post hoc tests indicate that the session effect was small but significant in the Text Diaries group $(\mathrm{t}(32)=2.81$, $\mathrm{p}=.008$, Cohen's $\mathrm{d}=0.35$ ), confirming our hypothesis.

Descriptive statistics show that participants that were exposed to the Text or Audio Dementia Diaries had on average lower negative attitude scores in the second session (Audio: $\mu=2.50, \sigma=0.50$; Text: $\mu=2.40, \sigma=0.37$ ) compared to the first session (Audio: $\mu=2.60, \sigma=0.37$; Text: $\mu=2.52, \sigma=0.34$ ). We observe this effect to be most prominent in the statement: 'Most people with dementia should not be allowed to renew their driver's licenses.' However, for those in the Control and News Articles groups we observe the opposite pattern; slightly higher negative attitude scores in the second session (Control: $\mu=2.51, \sigma=0.49$; News: $\mu=2.42, \sigma=0.45$ ) compared to the first session (Control: $\mu=2.48$, $\sigma=0.49$; News: $\mu=2.33, \sigma=0.49$ ). We observe this contrasting tendency in the following statements: 'Many people with dementia are stingy and hoard their money and possessions.', 'Many people with dementia just live in the past.', 'I don't like it when people with dementia try to make conversation 
with me.', 'I personally would not want to spend much time with a person with dementia.' These findings support the notion that media produced by people with dementia themselves can reduce negative attitudes towards dementia.

4.3.4 Qualitative findings related to attitudinal changes. Below, we present qualitative analysis that contextualizes attitudinal change.

Normalizing the condition and recognizing discrimination Participants referred to how text and audio diaries revealed a new lens on dementia by showing daily life: reading the Text Diaries after the news articles in the interview, S102 shared "I feel like it's definitely more personal. It reveals more of day-to-day struggles, day-to-day life with dementia." S89 compared this to the news stories in terms of the affect that it encouraged: "The news articles-it kind of talked about the factors that might affect people with dementia. But the transcripts help to show how people live their lives, and make it seem as if it's not that bad, and that they're just trying to have fun. And just keep moving" [S89]. Though many students mentioned the ways that people with dementia worked to keep going despite the struggles they faced, even describing it as inspiring, some said they sensed depression in some of the recordings or found it sad to hear about the struggles that people described.

Hearing about daily life with dementia appeared to normalize the condition for some: S16 said that, "I guess I was kind of surprised at how normal their lives seem to be." Though above we discuss how struggles were seen as depressing or inspirational, students also described how seeing struggles could be humanizing:

"I think it was useful to really learn a little bit more about dementia, especially seeing into personal stories. Seeing that people with dementia can actually remember some of their experiences that they went through and they can write about it, their feelings, and what they thought about it and show frustrated they feel. So I think it really helps show people, how they actually are as a person and not like you know, a person with dementia." [S10]

"It just gives more of a personal touch to the message. fust to get across that - you knowthey have normal lives just like us. We go through things and overcome them." [S68]

Some students such as S9 reflected on how their own attitudes prior to encountering this content might contribute to negative aspects of living with dementia: "I felt like before I would judge and kind of just assume about dementia. That people would forget and like they can't really handle themselves but then seeing how they get frustrated by people thinking that, and like it doesn't help for them to be confined to their own selves and like they need to get out in the world in order to feel more normalized." While not all students connected stigmatizing consequences (such as the frustration and confinement mentioned in the last quote) back to their own actions, others also mentioned beginning to recognize the link between others' expectations and the resources available to people with dementia. S61 described how the diaries helped them understand the existence of the "discrimination against people with dementia," where people "aren't seen as equivalent in society, that they're looked down upon and that they shouldn't be given the same opportunities" [S61]. Yet several students were not quite convinced by the content: for example, S42 was discussing a recording where "that one person was talking about how people with dementia are treated differently." They said they found this comparison "unfair," citing the memory issues that accompanied dementia but not cancer. Others mentioned some discomfort with the idea that people with dementia were engaging in activities such as traveling.

Audio diaries more personal than text diaries Descriptive statistics from $\mathrm{H} 3$ indicate that the largest differences in scores on the statements which showed larger dif ences between sessions - about admiring coping skills of people with dementia and the ability to improve lives of people with dementia - came from the audio condition. At the same time, the Text Diaries condition 
confirmed our hypothesis that dementia-related media can af negative attitudes, while the changes in the Audio Diaries were not significant (though with a similar trend). Our analysis below reveals the ways that audio was perceived as more personal and revealing by many students which may have resulted in some students locating and describing characteristics of dementia in ways that were less positive.

Many students noted that, due to accent and audio quality, the Dementia Diaries audio was less clear than the transcripts. Yet, many still found the audio to be more personal compared to the transcripts. They mentioned the audio as evoking more emotions and even sympathy compared to transcripts: "I think [that] I'm hearing it makes it sound more real coming from a person, their tone of voice. Even when he said it, his tone was like "try to see it from my perspective"... but hearing someone say it for themselves really breaks into perspective." [S67]

Individuals also described qualities such as enthusiasm and sadness which were audible in the audio recordings, which led S76 to share that, "hearing it I was more empathetic and I was feeling what they were feeling more. Reading it was just, eh... The recordings were way more genuine - you could hear their tones."

The vast majority of participants did not describe noticing or being bothered by symptoms of dementia such as stumbling over words or hesitation in the audio recordings. However, a few students did mention characteristics that stood out as indicating dementia: S53 said some of the recordings, "sounded very repetitive and there wasn't a point to what they were trying to say" and S101 noted when they went from the transcript to the audio recording in the interview where they got to view all stimuli, they were surprised: "I didn't expect her to speak as slowly, because the way it was written... When she started speaking you could tell that she had a problem."

Takeaways related to improving life with dementia Linked to the quantitative finding (in $\mathrm{H} 3$ analysis) that all groups except control increased scores answering the question "We can do a lot now to improve the lives of people with dementia," students described three related takeaways. First, while many students described being relieved that there was more support for people with dementia than they had realized, they also described a new recognition of the need for support for people with dementia to engage in daily life. Students also described a need to treat people with dementia as individuals: as S22 said, "I've never really been able to hear from so many different people's perspectives. And I think it was really useful in that it really demonstrated how they are able to lead fairly normal lives and that they have their own ways of thinking... When people are interacting with them, they have to take these patterns of thought into consideration as well." Finally, students reflected on how they might approach the topic of dementia in their own lives. S94 reconsidered the jokes and laughter that came at the expense of people with dementia, saying "it's honestly making me view those-that content in more of a negative light now." S89 said, "this just helps to bring more awareness to it, like you shouldn't treat them as different," and S94 discussed the topic in the context of advocacy and taboo:

"...I think people should understand that it's not a taboo topic - it's ok to talk about and it's ok to get more money, more facilities, and more funding for people with dementia. It's not a big deal to just talk about it out in the open, raise questions about it with politicians. It shouldn't be hidden away - people should understand that they're [people with dementia] still people - just because they have this condition or disease, they're still people."

\section{DISCUSSION}

CSCW researchers have long studied how marginalized or stigmatized populations produce online content to express priorities and engage in activism. Yet, little work considers how this content 
affects others, and whether this content achieves the oft-stated goals of changing attitudes or raising awareness.

Here, we revisit our two research questions. Our first research question asked how does media format (audio vs. text) and content producer (someone with dementia vs. someone without dementia) affect understanding of dementia? We hypothesized that exposure to dementia-related media would affect understanding of dementia. Though we found some qualitative evidence of changes in dementia understanding reflected in participants responses to post intervention interviews, our hypothesis was not confirmed through the quantitative analysis - there were no statistically significant changes to understanding in the dementia-related media conditions.

The second research question asked how does media format (audio vs. text) and content producer (someone with dementia vs. someone without dementia) affect attitudes towards people with dementia? We answered this research question by using three instruments, to assess positive, overall, and negative attitudes. We hypothesized that exposure to dementia-related media (Dementia Diaries and the news condition) would affect attitudes.

In regards to positive and overall attitudes, this hypothesis was confirmed as scores on these instruments significantly changed in the intervention conditions. However, there was also a statistically significant change for students in the control group, who did not interact with any dementia-related media. In other words, all the media formats and content producers that we tested, as well no intervention at all, improved attitudes. And while these increases were more noticeable for students in the conditions where the content producer was a person with dementia (the text and audio Dementia Diaries groups), our study was underpowered due to COVID-19 and the differences between conditions are not conclusive. There is an opportunity for future research to extend this study with a larger sample size.

We did see support for our hypothesis that dementia-related media could affect negative attitudes. This hypothesis was confirmed only for the Text Diaries intervention, where negative attitudes became less negative. While we observed a similar trend for Audio Diaries, it was not significant. In contrast, this trend was not present at all in the Control and News Articles groups.

Based on our findings that engaging with the topic of dementia (even in a limited way in the control condition) can improve positive and overall attitudes, interacting with content produced by people with dementia can decrease negative attitudes in some cases (the Text condition), and qualitative findings describing the impact of dementia media, we identify implications in three main areas: (1) supporting people with dementia in sharing their perspectives, (2) doing so in ways that best affect attitudes and understanding by reviewing our findings in terms of theories on cues and interactive media and, (3) implications for supporting students in changing their perspectives towards people with dementia.

\subsection{Supporting People with Dementia as Content Producers}

In centering the accounts of people with dementia themselves, our research works towards better balancing the media available on dementia. Past research has found that while dementia is discussed in the media, the perspective of people with dementia is typically missing $[18,55,106]$. One analysis of North American magazines found that, "there is virtually nothing said about the needs and desires of the person, or from the perspective of the person, who has been diagnosed. The diagnosed person is essentially voiceless, and his or her world is described by others-whether caregivers, medical personnel, or other experts" and there is an "absence of the person with the disease as a person with a voice, with needs and desires" [18]. In contrast, accounts of other conditions often feature first person experiences $[18,55]$.

As a field which has engaged in studying and supporting content production by lay people, including older adults $[10,91,114]$, CSCW is a fitting field to study and support people with 
dementia in this space. We draw three links below. First, the work of the content producers with dementia in this study represents a way of seeing social media generated by people with dementia - as a population that is frequently not featured in the many dialogues about them - as political. Given the power dynamics that exist such as people with dementia being denied access to resources taken for granted in everyday life [3], HCI researchers have pushed for this more political view of dementia in the past [76]. We posit that offering insight into everyday experiences may be a route to public-facing citizenship because it contrasts so sharply with the dominant narrative of dementia, which is external, end-focused, and medical.

Second, there are opportunities to support people with dementia in sharing online by joining efforts with researchers studying anti-harassment efforts (e.g., [8]) and the cultivation of safe spaces [96] for marginalized groups. Past research notes that people with dementia perceive the Dementia Diaries project as a safe space to share personal expressions, even though they know that their posts may be read by a wide audience [62]. Though some Dementia Diaries are posted to Twitter, many only exist on the website, reducing the public's opportunity to come across these accounts. Given that dementia is currently spoken about in very stigmatizing ways on social media $[16,74]$, it is key to pre-emptively decrease the discrimination people with dementia may face online if we wish to further benefit from people with dementia feeling comfortable expressing themselves online.

Third, we return to past literature that indicates that many individuals may not regularly encounter personal accounts by people with dementia. Students described little exposure to lived experiences of dementia, with online exposure largely to medical framings of dementia. Past research supports and explains this finding. A study that examined tweets related to dementia found many links to news stories, with the most frequent tweets related to research studies, largely around risk and and detection [94]. The most followed users in this sample were large organizations which did not post any content that can be characterized as personal anecdotes or experiences [94]. And, following account holders with dementia will not necessarily result in exposure to more personal experiences: a study of Twitter account holders with dementia found that the majority of tweets are not focused on personal experiences, but rather purposes such as lobbying and advocacy [103]. There is a need to support people with dementia in sharing their experiences and to make this content more accessible to others. One avenue is in bringing sharing or broadcasting options to easily post content from organizations' platforms to mainstream sites such as Facebook or Twitter (e.g., through API integration as in [11]). Another way to build exposure to this content is through formal education, which we turn to in 5.3.

A final point about studying and supporting people with dementia in sharing their accounts draws not on CSCW research, but on the critical disability literature. Some of our findings may lead us in the direction of inspirational content around dementia - the Dementia Diaries content students interacted with had largely positive sentiment, students described positive reactions to content where people with dementia were engaged in activities, and there was an increase in scores on the question asking about whether people were inspired by dementia. Further, people with dementia may have an inclination to represent positive stories to counteract the predominant accounts of dementia [103]. But, there is need to pause before coming to the conclusion that positive stories should be the main focus given that people with disabilities can be objectified and otherwise negatively impacted by what has been termed "inspiration porn," or wonder and amazement associated with ordinary activities of daily living [81]. Additionally, showing only people who are able to navigate their environments can continue to emphasise productivity, rationality, and cognition in a way that further marginalizes people with dementia [88] and removes a sense of responsibility from the listeners to create a world that is more livable for individuals with dementia At the same time, while there are open questions around what sentiment yields the most positive

Proc. ACM Hum.-Comput. Interact., Vol. 5, No. CSCW2, Article 398. Publication date: October 2021. 
impact, what is more conclusive from this study is the current gap in terms of exposure to content on everyday, lived experiences with dementia, with medicalized narratives of people at later stages of dementia far more prevalent.

\subsection{Reviewing Findings in Light of Cues and Interactive Media Research}

Above, we discuss opportunities to support people with dementia in sharing content. Here, we discuss our findings in terms of implications for designing interventions in ways that have the most potential to affect attitudes and understanding.

Reviewing our intervention and findings in terms of work on cues, students spoke in-depth in the interviews about the emotions that they registered in the audio. These findings are consistent with some theories where the personality and tonal characteristics that are embedded in nonverbal cues play a role in persuasion and attitudinal change [112]. Recognizing the importance of content delivery such as "gestures, eye movements, the use of other persons (and bodies)" also appears in a review of stories, disabilities, and illness [45] and reflects a shifting emphases in dementia design research $[20,63,77,78,109]$. Our findings, in the context of these literatures, might lead us to recommend interventions that show even more nonverbal cues, such as through video or VR. Kuchelmeister et al. pick up this direction, with a Virtual Reality experience developed to confront stereotypes by psychologists and a woman living with dementia. This project which strives to draw people into the world of a person living with dementia - in contrast to simulation VR, this project has the viewer able to witness and interact with the animated individual with dementia in order to confront stereotypes [59].

And yet, it is key to note that negative attitudes were significantly reduced in the text condition - but not significantly in the other conditions. This finding does not contradict the results of the other two scales of attitudes, where positive and overall attitudes improved across each condition. Though positive and negative attitudes are often thought of as opposite ends of a spectrum, they are theoretically distinct concepts [85]. Functionally, they are distinct as well: negative attitudes can be used to predict negative behaviors, such as hostility, while positive attitudes predict positive behaviors [85]. Deciding whether to intervene on positive or negative attitudes may depend on the goal of the project - if it is to foster collaboration with another group in a user-centered design project, for example, then positive attitudes may be most important to change. If the goal is to prevent discriminatory behaviors towards a group (a potentially fruitful area for future CSCW research), then negative attitudes may be most important to target.

We do not have conclusive evidence to explain why negative attitudes changed significantly in the Dementia Diaries text condition, while in the audio condition there was a similar trend but not significant results. It is possible that there are some elements to the audio recordings, when compared to text transcripts, that limit negative attitudinal change. Qualitative data indicates some potential reasons: individuals described "feeling what they were feeling more" in audio recordings, and if students perceived negative emotions in the content these may have become been more salient. Further, though not mentioned by the majority of participants, some individuals mentioned cognitive impairment being detectable in the recordings due to repetition or slow speaking pace: in a world where these signs of dementia are so stigmatizing, they may have dampened attitudinal changes. Reviewing this finding in terms of past communication and media studies research, there is some evidence that fewer cues may mean that restrictive social norms play a smaller role - as listeners use cues to make judgements such as about intelligence and compatibility [117]. Another potential explanation comes from Walter et al.'s past work comparing the effect of audiovisual and text formats in order to change attitudes towards Pap tests to prevent cervical cancer [110]. They found that the richer medium of the audiovisual format may better catch attention and present emotional cues when compared to text conditions, they also may bring up negative, oppositional 
reactions in the audience - potentially by threatening their sense of control over how to take in a message [110].

In terms of understanding, we did not find significant results. Though many past interventions did find changes in understanding, one study using a person-centered view of dementia in an online module also did not find changes in understanding [52]. Examining the instrument we used to assess understanding, both findings that lack of significant effects may be due to the ways that scales to assess understanding in dementia are largely built around characterizing the condition in terms of risks, diagnosis, and symptoms. They may exhibit medicalized views of dementia, rather than person-centered or critical dementia notions regarding appropriate support, capabilities, and agency.One direction forward would be to involve the population in creating or selecting the scales that measure the changes that they would like to see through the content they share, similar in philosophy to a shift to patient-reported outcomes in healthcare.

\subsection{Improving Student Attitudes Toward and Understanding of Dementia}

Here, we discuss our findings as they can be applied to improve students attitudes towards and understanding of dementia. We do so by discussing our work in relation to past interventions with students towards similar goals.

The majority of past interventions that aim to change student perspectives of people with dementia show positive impact [118], perhaps due to a low baseline that people start with given the fear and stigma surrounding the condition. Our finding that overall and positive attitudes changed across all conditions, including the control, may provide some explanation for these past findings - simply expressing one's attitudes, understanding, and experience with dementia appears to improve attitudes towards this condition. Consequently, simply bringing up and asking students to reflect on the topic of dementia may be a fruitful effort.

Past interventions to change student attitudes towards dementia range in terms of time, from a 10 minute dementia simulation [22] to 15 weeks of interactions [47]. Our study represents an approach on the shorter end of the spectrum. Finding some positive results, particularly since our post-test took place weeks after the intervention, indicates that increasing student exposure to experiences of people with dementia, even briefly, may lead to improved attitudes. Instructors can take away that inserting even a brief discussion of the topic into a curricula may have positive effects: there is not a need to insert many weeks of content to have an impact on attitudes towards dementia.

In terms of what content might be brought into curricula, past research on how instructors teach accessibility at United States universities found that an existing strategy to help people understand and appreciate the experience of people with diverse disabilities is to include videos [90]. Our findings offer evidence that brief first-person accounts of living with dementia in the form of audio or written narratives may also be useful for course content. The Dementia Diaries website can be a useful resource for instructors, and there are also opportunities to collect and share Diaries which best link to learning objectives [90].

The type of intervention past researchers have deployed to change student perspectives of dementia vary significantly. This includes interventions that do not involve people with dementia directly, primarily in the form of dementia simulations that students interact with as part of a class $[22,34,53,95]$. Other interventions are centered around direct involvement with people with dementia, through service learning or clinical training as part of their curricula (e.g., [52]), or social or art-based activities (e.g., [121]). Reflecting on these prior modes of interventions yields two further considerations.

First, nearly all of these past interventions with students take place in person. One exception is reported in a study with students in a community health course, where one of the intervention 
conditions was an online module which covered topics including cognitive assessment, personcentered care, and understanding and working with changes in thinking and communication in people with dementia [52]. The attitudes of students in this condition improved only slightly (as did students in the control group), while students who worked with people with dementia directly as part of a clinical rotation experienced a significant change in attitude [52]. Another study, involving an exclusively online component, created and trialled a 4-week online dementia case study. The goals of this study differ from ours, in that they sought to (and find promising results in terms of) promoting comfort, self-perceived ability, and perceived value in working in interprofessional teams [14]. Aside from these examples, few studies intervening in student attitudes have taken place remotely. Our study offers a useful approach as we see an increase in online education and CSCW researchers deepen their relationship with the field of education [113]. There are opportunities to work with experts in education and educational technology to investigate approaches to scaffold different kinds of material, for example with content to aid understanding, correct misperceptions students had, or give space for reflection.

Second, while many interventions notably center interaction with people with dementia [118], these engagements are typically in the moment, or synchronous interaction where people spend time together focused on a clinical task or an arts-based activity. Past research confirms the importance of focusing on interactions in the present moment with people with dementia (i.e., rather than relying on the ability to recall prior interactions or experiences) [28, 51, 63, 77]. And as valuable as these opportunities are, we argue that it is also key to make space for people with dementia to articulate and share their priorities in ways that may not be best supported in synchronous interaction. This can involve the resource-intensive approach of creating and compensating working groups with people with dementia, but educators may benefit by partnering with organizations who are already working towards this goal.

The majority of the interventions described above focus on students in health fields. Are there special considerations for working with technology students? Some needs identified in past technology design research with people with dementia align with what can be achieved through our intervention, such as bridging the gaps between the views and experience of individuals with dementia and researchers in design [70] and centering epistemological understandings [24] or situated insights [82] on dementia in order to envision technological futures. Yet other needs, such as smoothing interactions between people with dementia and those without experience with this population [30,115] indicate that interacting with recorded media might not always be enough. Further, our intervention does not feature people with more advanced dementia. To speak to this gap, we can turn to Foley et al.'s study of the experience of eight undergraduate students who were engaged in co-design with people with dementia. Several findings resonate with our work: students developed understandings that differed from what they had learned in their classes, including the variability of what it means to live with dementia and surprise at abilities looking different than their assumptions (e.g., residents being able to remember their names), as well as an eagerness to normalize the experiences of people with dementia. However, this project also found a key cultivation of personal relationships [29], which is a different kind of outcome than what might be achieved through receiving asynchronous expressions from people with dementia. The ideal approach may be one that mixes supporting interaction with people with dementia to cultivate relationships and relational skills, as well as scaled exposure to priorities that people with dementia have identified.

\section{CONCLUSION}

Social media is often framed as providing a platform for the voices of people who would otherwise not be heard, and online social movements by marginalized groups have received significant interest 
in CSCW [2, 67]. However, researchers have not typically focused on the individuals who receive these online expressions to determine whether the impact on viewers matches the goals of the content producers. Though our study only measured changes over a short period, it offers insights into how a sample of undergraduate students make sense of content produced by people with dementia, as well as changes in their attitudes and understanding after they were exposed to a variety of content about dementia. Though we did not find any effect of the interventions on understanding as measured by existing instruments, there were significant changes in terms of changes in attitude. Positive and overall attitudes changed across each condition, including the control group. Negative attitudes improved in the Dementia Diaries text condition, where students interacted with transcripts of recordings produced by people with dementia.

Our study design and findings have implications for other researchers looking to "close the loop" in social media research - to study the effect of content as well as the ways that it is produced. The work we present in this paper represents a first step towards understanding how content produced by people with dementia may contribute to attitude change and ultimately efforts to reduce discrimination towards this population. While our focus in this paper is on undergraduate students with some implications in more formal learning scenarios, people who do not attend college and people outside of a college setting can also be supported in improving attitudes and understanding towards dementia and other disabilities. There is much opportunity for research in this space.

\section{ACKNOWLEDGMENTS}

Thank you to Snehal Bedmutha, Himanshi Manglunia, and Shruti Hegde for assisting in managing data collection, and Hanuma Teja Maddali, Alisha Pradhan, Kian Abdi, Jesse Anderson, Benjamin Cohn, Stephen Dziwura, Aarthi Ganesh, Immanuel Garcia, Aakriti Khanal, Sonia Morgan, and Hong Tu for assisting with data collection. We appreciate early conversations with Jessica Vitak on planning study design. Thank you to those involved in the Dementia Diaries project for allowing us to use their recordings in this study.

This project was supported, in part, by the National Science Foundation under award IIS-2045679 and a NIDILRR Rehabilitation Engineering Research Center grant, \#90REGE0008, from the U.S. Admin. for Community Living, Dept. of Health \& Human Services. Points of view or opinions are those of the authors and do not necessarily represent official ACL policy.

\section{REFERENCES}

[1] Nazanin Andalibi, Margaret E. Morris, and Andrea Forte. 2018. Testing Waters, Sending Clues: Indirect Disclosures of Socially Stigmatized Experiences on Social Media. Proc. ACM Hum.-Comput. Interact. 2, CSCW, Article 19 (Nov. 2018), 23 pages. https://doi.org/10.1145/3274288

[2] Brooke E. Auxier, Cody L. Buntain, Paul Jaeger, Jennifer Golbeck, and Hernisa Kacorri. 2019. \#HandsOffMyADA: A Twitter Response to the ADA Education and Reform Act. In Proceedings of the 2019 CHI Conference on Human Factors in Computing Systems (Glasgow, Scotland Uk) (CHI '19). Association for Computing Machinery, New York, NY, USA, 1-12. https://doi.org/10.1145/3290605.3300757

[3] Ruth Bartlett and Deborah O'Connor. 2007. From personhood to citizenship: Broadening the lens for dementia practice and research. Journal of Aging Studies 21, 2 (2007), 107-118.

[4] Anne Davis Basting. 2003. Looking back from loss: Views of the self in Alzheimer's disease. Journal of Aging Studies 17,1 (2003), 87-99.

[5] Renée L Beard, Jenny Knauss, and Don Moyer. 2009. Managing disability and enjoying life: How we reframe dementia through personal narratives. Fournal of Aging Studies 23, 4 (2009), 227-235.

[6] Susan M Behuniak. 2011. The living dead? The construction of people with Alzheimer's disease as zombies. Ageing \& Society 31, 1 (2011), 70-92.

[7] Cynthia L Bennett and Daniela K Rosner. 2019. The Promise of Empathy: Design, Disability, and Knowing the" Other". In Proceedings of the 2019 CHI Conference on Human Factors in Computing Systems. 1-13. 
[8] Lindsay Blackwell, Jill Dimond, Sarita Schoenebeck, and Cliff Lampe. 2017. Classification and its consequences for online harassment: Design insights from heartmob. Proceedings of the ACM on Human-Computer Interaction 1, CSCW (2017), 1-19.

[9] Virginia Braun and Victoria Clarke. 2006. Using thematic analysis in psychology. Qualitative research in psychology 3 , 2 (2006), 77-101.

[10] Robin Brewer and Anne Marie Piper. 2016. "Tell It Like It Really Is": A Case of Online Content Creation and Sharing Among Older Adult Bloggers. In Proceedings of the 2016 CHI Conference on Human Factors in Computing Systems (San Jose, California, USA) (CHI '16). Association for Computing Machinery, New York, NY, USA, 5529-5542. https://doi.org/10.1145/2858036.2858379

[11] Robin N Brewer and Anne Marie Piper. 2017. xPress: Rethinking design for aging and accessibility through an IVR blogging system. Proceedings of the ACM on Human-Computer Interaction 1, CSCW (2017), 1-17.

[12] Julian Brinkley. 2020. Participation at What Cost? Teaching Accessibility Using Participatory Design: An Experience Report. In Proceedings of the 51st ACM Technical Symposium on Computer Science Education (Portland, OR, USA) (SIGCSE '20). Association for Computing Machinery, New York, NY, USA, 114-120. https://doi.org/10.1145/3328778.3366931

[13] Brian D Carpenter, Steve Balsis, Poorni G Otilingam, Priya K Hanson, and Margaret Gatz. 2009. The Alzheimer's Disease Knowledge Scale: development and psychometric properties. The Gerontologist 49, 2 (2009), 236-247.

[14] Jade Cartwright, Diane Franklin, Dawn Forman, and Heather Freegard. 2015. Promoting collaborative dementia care via online interprofessional education. Australasian journal on ageing 34, 2 (2015), 88-94.

[15] Sheung-Tak Cheng, Linda CW Lam, Liliane CK Chan, Alexander CB Law, Ada WT Fung, Wai-chi Chan, Cindy WC Tam, and Wai-man Chan. 2011. The effects of exposure to scenarios about dementia on stigma and attitudes toward dementia care in a Chinese community. International Psychogeriatrics 23, 9 (2011), 1433-1441.

[16] Tiffany Yi-Mei Cheng, Lisa Liu, and Benjamin KP Woo. 2018. Analyzing Twitter as a platform for Alzheimer-related dementia awareness: thematic analyses of tweets. FMIR aging 1, 2 (2018), e11542.

[17] Sora Choi and Myonghwa Park. 2017. Student participation in a dementia-outreach research project as communitybased experiential learning. Educational Gerontology 43, 4 (2017), 186-197.

[18] Juanne N Clarke. 2006. The case of the missing person: Alzheimer's disease in mass print magazines 1991-2001. Health communication 19, 3 (2006), 269-276.

[19] Miri Cohen, Perla Werner, and Faisal Azaiza. 2009. Emotional reactions of Arab lay persons to a person with Alzheimer's disease. Aging and Mental Health 13, 1 (2009), 31-37.

[20] Jiamin Dai and Karyn Moffatt. 2020. Making Space for Social Sharing: Insights from a Community-Based Social Group for People with Dementia. In Proceedings of the 2020 CHI Conference on Human Factors in Computing Systems (Honolulu, HI, USA) (CHI '20). Association for Computing Machinery, New York, NY, USA, 1-13. https://doi.org/10. $1145 / 3313831.3376133$

[21] Debby Damen, Per van der Wijst, Marije van Amelsvoort, and Emiel Krahmer. 2020. The Effect of Perspective-Taking on Trust and Understanding in Online and Face-to-Face Mediations. Group Decision and Negotiation 29, 6 (2020), 1121-1156.

[22] Izabella Dutra De Abreu, Marilyn Hinojosa-Lindsey, and Ali Abbas Asghar-Ali. 2017. A simulation exercise to raise learners' awareness of the physical and cognitive changes in older adults. Academic Psychiatry 41, 5 (2017), 684-687.

[23] Melvin L DeFleur, Lucinda Davenport, Mary Cronin, and Margaret DeFleur. 1992. Audience recall of news stories presented by newspaper, computer, television and radio. Fournalism Quarterly 69, 4 (1992), 1010-1022.

[24] Emma Dixon and Amanda Lazar. 2020. Approach Matters: Linking Practitioner Approaches to Technology Design for People with Dementia. In Proceedings of the 2020 CHI Conference on Human Factors in Computing Systems (Honolulu, HI, USA) (CHI '20). Association for Computing Machinery, New York, NY, USA, 1-15. https://doi.org/10.1145/3313831. 3376432

[25] Jeannette Durick, Toni Robertson, Margot Brereton, Frank Vetere, and Bjorn Nansen. 2013. Dispelling ageing myths in technology design. In Proceedings of the 25th Australian Computer-Human Interaction Conference: Augmentation, Application, Innovation, Collaboration. 467-476.

[26] Joanna Evans, Michael Brown, Tim Coughlan, Glyn Lawson, and Michael P Craven. 2015. A systematic review of dementia focused assistive technology. In International conference on human-computer interaction. Springer, 406-417.

[27] Jasper Feine, Ulrich Gnewuch, Stefan Morana, and Alexander Maedche. 2019. A taxonomy of social cues for conversational agents. International fournal of Human-Computer Studies 132 (2019), 138-161.

[28] Sarah Foley, Nadia Pantidi, and John McCarthy. 2019. Care and design: an ethnography of mutual recognition in the context of advanced dementia. In Proceedings of the 2019 CHI Conference on Human Factors in Computing Systems. 1-15.

[29] Sarah Foley, Nadia Pantidi, and John McCarthy. 2020. Student Engagement in Sensitive Design Contexts: A Case Study in Dementia Care. In Proceedings of the 2020 CHI Conference on Human Factors in Computing Systems (Honolulu, HI, USA) (CHI '20). Association for Computing Machinery, New York, NY, USA, 1-13. https://doi.org/10.1145/3313831 
3376161

[30] Pin Sym Foong, Shengdong Zhao, Kelsey Carlson, and Zhe Liu. 2017. VITA: Towards Supporting Volunteer Interactions with Long-Term Care Residents with Dementia. In Proceedings of the 2017 CHI Conference on Human Factors in Computing Systems. 6195-6207.

[31] Maryann Fraboni, Robert Saltstone, and Susan Hughes. 1990. The Fraboni Scale of Ageism (FSA): An attempt at a more precise measure of ageism. Canadian fournal on Aging/La revue canadienne du vieillissement 9, 1 (1990), 56-66.

[32] Ryan J. Gallagher, Elizabeth Stowell, Andrea G. Parker, and Brooke Foucault Welles. 2019. Reclaiming Stigmatized Narratives: The Networked Disclosure Landscape of \#MeToo. Proc. ACM Hum.-Comput. Interact. 3, CSCW, Article 96 (Nov. 2019), 30 pages. https://doi.org/10.1145/3359198

[33] Daniel R George, Heather L Stuckey, and Megan M Whitehead. 2013. An arts-based intervention at a nursing home to improve medical students' attitudes toward persons with dementia. Academic Medicine 88, 6 (2013), 837-842.

[34] Julia F-M Gilmartin-Thomas, John McNeil, Anne Powell, Daniel T Malone, Rory Wolfe, Ian C Larson, Claire L O’Reilly, Carl M Kirkpatrick, Eva Kipen, Tanya Petrovich, et al. 2018. Impact of a virtual dementia experience on medical and pharmacy students' knowledge and attitudes toward people with dementia: a controlled study. fournal of Alzheimer's Disease 62, 2 (2018), 867-876.

[35] Timothy J Grigsby, Jennifer B Unger, Gregory B Molina, and Mel Baron. 2017. Evaluation of an audio-visual novela to improve beliefs, attitudes and knowledge toward dementia: a mixed-methods approach. Clinical Gerontologist 40, 2 (2017), 130-138

[36] Nancy M Harding, Nancy Harding, and Colin Palfrey. 1997. The social construction of dementia: Confused professionals? Macmillan.

[37] D. Fox Harrell. 2009. Computational and Cognitive Infrastructures of Stigma: Empowering Identity in Social Computing and Gaming. In Proceedings of the Seventh ACM Conference on Creativity and Cognition (Berkeley, California, USA) (C\&C '09). Association for Computing Machinery, New York, NY, USA, 49-58. https://doi.org/10.1145/1640233.1640244

[38] Phyllis Braudy Harris and Cynthia Anne Caporella. 2014. An intergenerational choir formed to lessen Alzheimer's disease stigma in college students and decrease the social isolation of people with Alzheimer's disease and their family members: A pilot study. American fournal of Alzheimer’s Disease \& Other Dementias ${ }^{\circledR} 29,3$ (2014), $270-281$.

[39] Phyllis Braudy Harris and Cynthia Anne Caporella. 2019. Making a university community more dementia friendly through participation in an intergenerational choir. Dementia 18, 7-8 (2019), 2556-2575.

[40] Jan Heim, Trude Asting, and Trond Schliemann. 2002. Medium effects on persuasion. In Proceedings of the second Nordic conference on Human-computer interaction. 259-262.

[41] Lynn K Herrmann, Elisabeth Welter, James Leverenz, Alan J Lerner, Nancy Udelson, Cheryl Kanetsky, and Martha Sajatovic. 2018. A systematic review of dementia-related stigma research: can we move the stigma dial? The American fournal of Geriatric Psychiatry 26, 3 (2018), 316-331.

[42] Catherine Holloway. 2019. Disability Interaction (DIX): A Manifesto. Interactions 26, 2 (Feb. 2019), 44-49. https: //doi.org/10.1145/3310322

[43] Muhammad Hossain, John Crossland, Rebecca Stores, Ann Dewey, and Yohai Hakak. 2020. Awareness and understanding of dementia in South Asians: A synthesis of qualitative evidence. Dementia 19, 5 (2020), 1441-1473.

[44] Agnes Houston. 2018. Dementia \& Sensory Challenges: Dementia Can be More Than Memory. Dementia Centre.

[45] Lars-Christer Hydén and Eleonor Antelius. 2011. Communicative disability and stories: Towards an embodied conception of narratives. Health: An Interdisciplinary fournal for the Social Study of Health, Illness and Medicine 15, 6 (2011), 588-603.

[46] Alzheimer's Disease International. [n.d.]. Dementia Friendly Communities - Key Principles. https://www.alz.co.uk/ adi/pdf/dfc-principles.pdf

[47] Wafaa A Kaf, Linda S Barboa, Bradley J Fisher, and Lydia A Snavely. 2011. Effect of interdisciplinary service learning experience for audiology and speech-language pathology students working with adults with dementia. (2011).

[48] Saba Kawas, Laura Vonessen, and Amy J. Ko. 2019. Teaching Accessibility: A Design Exploration of Faculty Professional Development at Scale. In Proceedings of the 50th ACM Technical Symposium on Computer Science Education (Minneapolis, MN, USA) (SIGCSE '19). Association for Computing Machinery, New York, NY, USA, 983-989. https://doi.org/10. $1145 / 3287324.3287399$

[49] Matthew Kay, Cynthia Matuszek, and Sean A. Munson. 2015. Unequal Representation and Gender Stereotypes in Image Search Results for Occupations. In Proceedings of the 33rd Annual ACM Conference on Human Factors in Computing Systems (Seoul, Republic of Korea) (CHI '15). Association for Computing Machinery, New York, NY, USA, 3819-3828. https://doi.org/10.1145/2702123.2702520

[50] Claire Kearney-Volpe, Devorah Kletenik, Kate Sonka, Deborah Sturm, and Amy Hurst. 2019. Evaluating Instructor Strategy and Student Learning Through Digital Accessibility Course Enhancements. In The 21st International ACM SIGACCESS Conference on Computers and Accessibility (Pittsburgh, PA, USA) (ASSETS '19). Association for Computing Machinery, New York, NY, USA, 377-388. https://doi.org/10.1145/3308561.3353795 
[51] Candace L Kemp, Alexis A Bender, Joy Ciofi, Jennifer Craft Morgan, Elisabeth O Burgess, Stephen Duong, Fayron R Epps, Andrea Michelle Hill, Pamela R Manley, Jasmine Sease, et al. 2021. Meaningful Engagement Among Assisted Living Residents With Dementia: Successful Approaches. Journal of Applied Gerontology (2021), 0733464821996866.

[52] Michelle Kimzey, Beth Mastel-Smith, and Danita Alfred. 2016. The impact of educational experiences on nursing students' knowledge and attitudes toward people with Alzheimer's disease: A mixed method study. Nurse Education Today 46 (2016), 57-63.

[53] Michelle Kimzey, Jodi Patterson, and Beth Mastel-Smith. 2020. Effects of Simulation on Nursing Students' Dementia Knowledge and Empathy: A Mixed Method Study. Issues in Mental Health Nursing (2020), 1-6.

[54] Jennifer M Kinney, Takashi Yamashita, and J Scott Brown. 2017. Measuring positive attitudes toward persons with dementia: A validation of the Allophilia scale. Dementia 16, 8 (2017), 1045-1060.

[55] Allison M Kirkman. 2006. Dementia in the news: the media coverage of Alzheimer's disease. Australasian fournal on Ageing 25, 2 (2006), 74-79.

[56] Thomas Marris Kitwood and TM Kitwood. 1997. Dementia reconsidered: The person comes first. Vol. 20. Open university press Buckingham.

[57] Pia C Kontos. 2004. Ethnographic reflections on selfhood, embodiment and Alzheimer's disease. Ageing \& Society 24 , 6 (2004), 829-849.

[58] Liliia Korol, Alexander W Fietzer, and Joseph G Ponterotto. 2018. The relationship between multicultural personality, intergroup contact, and positive outgroup attitudes toward Asian Americans. Asian American fournal of Psychology 9 , 3 (2018), 200.

[59] V. Kuchelmeister, J. Bennett, N. Ginnivan, G. Kenning, C. Papadopoulos, B. Dean, and M. Neidorf. 2020. The Visit. In 2020 IEEE Conference on Virtual Reality and 3D User Interfaces Abstracts and Workshops (VRW). 853-854. https://doi.org/10.1109/VRW50115.2020.00278

[60] Jordan P LaBouff and Annie M Ledoux. 2016. Imagining atheists: Reducing fundamental distrust in atheist intergroup attitudes. Psychology of Religion and Spirituality 8, 4 (2016), 330.

[61] Richard E. Ladner and Matt May. 2017. Teaching Accessibility. In Proceedings of the 2017 ACM SIGCSE Technical Symposium on Computer Science Education (Seattle, Washington, USA) (SIGCSE '17). Association for Computing Machinery, New York, NY, USA, 691-692. https://doi.org/10.1145/3017680.3017804

[62] Amanda Lazar and Emma E. Dixon. 2019. Safe Enough to Share: Setting the Dementia Agenda Online. Proc. ACM Hum.-Comput. Interact. 3, CSCW, Article 85 (Nov. 2019), 23 pages. https://doi.org/10.1145/3359187

[63] Amanda Lazar, Caroline Edasis, and Anne Marie Piper. 2017. A Critical Lens on Dementia and Design in HCI. In Proceedings of the 2017 CHI Conference on Human Factors in Computing Systems (Denver, Colorado, USA) (CHI '17). Association for Computing Machinery, New York, NY, USA, 2175-2188. https://doi.org/10.1145/3025453.3025522

[64] Amanda Lazar, Jonathan Lazar, and Alisha Pradhan. 2019. Using Modules to Teach Accessibility in a User-Centered Design Course. In The 21st International ACM SIGACCESS Conference on Computers and Accessibility (Pittsburgh, PA, USA) (ASSETS '19). Association for Computing Machinery, New York, NY, USA, 554-556. https://doi.org/10.1145/ 3308561.3354632

[65] Sophie Lecheler and Claes H De Vreese. 2011. Getting real: The duration of framing effects. fournal of Communication 61, 5 (2011), 959-983.

[66] Sophie Lecheler and Claes H de Vreese. 2016. How long do news framing effects last? A systematic review of longitudinal studies. Annals of the International Communication Association 40, 1 (2016), 3-30.

[67] Hanlin Li, Disha Bora, Sagar Salvi, and Erin Brady. 2018. Slacktivists or Activists? Identity Work in the Virtual Disability March. In Proceedings of the 2018 CHI Conference on Human Factors in Computing Systems. 1-13.

[68] Christine Liebrecht and Charlotte van Hooijdonk. 2019. Creating humanlike chatbots: what chatbot developers could learn from webcare employees in adopting a conversational human voice. In International Workshop on Chatbot Research and Design. Springer, 51-64.

[69] Xialing Lin and Patric R Spence. 2018. Identity on social networks as a cue: Identity, retweets, and credibility. Communication Studies 69, 5 (2018), 461-482.

[70] Stephen Lindsay, Katie Brittain, Daniel Jackson, Cassim Ladha, Karim Ladha, and Patrick Olivier. 2012. Empathy, Participatory Design and People with Dementia. In Proceedings of the SIGCHI Conference on Human Factors in Computing Systems (Austin, Texas, USA) (CHI '12). Association for Computing Machinery, New York, NY, USA, 521-530. https://doi.org/10.1145/2207676.2207749

[71] Elizabeth Lokon, Yue Li, and Suzanne Kunkel. 2018. Allophilia: increasing college students' "liking" of older adults with dementia through arts-based intergenerational experiences. Gerontology \& geriatrics education (2018), 1-14.

[72] Beth Mastel-Smith, Michelle Kimzey, Jennifer Garner, Osama A Shoair, Eric Stocks, and Takova Wallace. 2019. Dementia care boot camp: interprofessional education for healthcare students. Fournal of Interprofessional Care (2019), 1-13. 
[73] Yukihisa Matsuda, Reiko Hashimoto, Sachiko Takemoto, Yuka Yoshioka, Takashi Uehara, and Yasuhiro Kawasaki. 2018. Educational benefits for nurses and nursing students of the dementia supporter training program in Japan. PLoS One 13, 7 (2018), e0200586.

[74] Nishila Mehta, Lynn Zhu, Kenneth Lam, Nathan M Stall, Rachel Savage, Stephanie H Read, Wei Wu, Paula Pop, Colin Faulkner, Susan E Bronskill, et al. [n.d.]. Health Forums and Twitter for Dementia Research: Opportunities and Considerations. Fournal of the American Geriatrics Society ([n. d.]).

[75] Rachel Menzies, Garreth W. Tigwell, Mandar Tamhane, and Annalu Waller. 2019. Weaving Accessibility Through an Undergraduate Degree. In The 21st International ACM SIGACCESS Conference on Computers and Accessibility (Pittsburgh, PA, USA) (ASSETS '19). Association for Computing Machinery, New York, NY, USA, 526-529. https: //doi.org/10.1145/3308561.3354611

[76] Kellie Morrissey, Amanda Lazar, Jennifer Boger, and Austin Toombs. 2017. HCIxDementia Workshop: The Role of Technology and Design in Dementia. In Proceedings of the 2017 CHI Conference Extended Abstracts on Human Factors in Computing Systems (Denver, Colorado, USA) (CHI EA '17). Association for Computing Machinery, New York, NY, USA, 484-491. https://doi.org/10.1145/3027063.3027083

[77] Kellie Morrissey, John McCarthy, and Nadia Pantidi. 2017. The Value of Experience-Centred Design Approaches in Dementia Research Contexts. In Proceedings of the 2017 CHI Conference on Human Factors in Computing Systems (Denver, Colorado, USA) (CHI '17). Association for Computing Machinery, New York, NY, USA, 1326-1338. https: //doi.org/10.1145/3025453.3025527

[78] Kellie Morrissey, Gavin Wood, David Green, Nadia Pantidi, and John McCarthy. 2016. 'I'm a Rambler, I'm a Gambler, I'm a Long Way from Home': The Place of Props, Music, and Design in Dementia Care. In Proceedings of the 2016 ACM Conference on Designing Interactive Systems (Brisbane, QLD, Australia) (DIS '16). Association for Computing Machinery, New York, NY, USA, 1008-1020. https://doi.org/10.1145/2901790.2901798

[79] P Karen Murphy, Theresa A Holleran, Joyce F Long, and Jill A Zeruth. 2005. Examining the complex roles of motivation and text medium in the persuasion process. Contemporary Educational Psychology 30, 4 (2005), 418-438.

[80] Michelle R Nario-Redmond, Dobromir Gospodinov, and Angela Cobb. 2017. Crip for a day: The unintended negative consequences of disability simulations. Rehabilitation psychology 62, 3 (2017), 324.

[81] Michelle R Nario-Redmond, Alexia A Kemerling, and Arielle Silverman. 2019. Hostile, benevolent, and ambivalent ableism: Contemporary manifestations. Journal of Social Issues 75, 3 (2019), 726-756.

[82] Renee Noortman, Britta F Schulte, Paul Marshall, Saskia Bakker, and Anna L Cox. 2019. HawkEye-Deploying a Design Fiction Probe. In Proceedings of the 2019 CHI Conference on Human Factors in Computing Systems. 1-14.

[83] Melissa L O'Connor and Susan H McFadden. 2010. Development and psychometric validation of the dementia attitudes scale. International fournal of Alzheimer's Disease 2010 (2010).

[84] World Health Organization et al. 2012. Dementia: a public health priority. World Health Organization.

[85] Todd L Pittinsky, Seth A Rosenthal, and R Matthew Montoya. 2011. Liking is not the opposite of disliking: The functional separability of positive and negative attitudes toward minority groups. Cultural Diversity and Ethnic Minority Psychology 17, 2 (2011), 134.

[86] Todd L Pittinsky, Seth A Rosenthal, and R Matthew Montoya. 2011. Measuring positive attitudes toward outgroups: Development and validation of the Allophilia Scale. (2011).

[87] Leslie Cartz Piver, Philippe Nubukpo, Angélique Faure, Nathalie Dumoitier, Philippe Couratier, and Jean-Pierre Clément. 2013. Describing perceived stigma against Alzheimer's disease in a general population in France: the STIG-MA survey. International journal of geriatric psychiatry 28, 9 (2013), 933-938.

[88] Stephen G Post. 1995. Dementia in our midst: The moral community. Cambridge Quarterly of Healthcare Ethics 4, 2 (1995), 142-147.

[89] Cynthia Putnam, Maria Dahman, Emma Rose, Jinghui Cheng, and Glenn Bradford. 2015. Teaching Accessibility, Learning Empathy. In Proceedings of the 17th International ACM SIGACCESS Conference on Computers \& Accessibility (Lisbon, Portugal) (ASSETS '15). Association for Computing Machinery, New York, NY, USA, 333-334. https: //doi.org/10.1145/2700648.2811365

[90] Cynthia Putnam, Maria Dahman, Emma Rose, Jinghui Cheng, and Glenn Bradford. 2016. Best Practices for Teaching Accessibility in University Classrooms: Cultivating Awareness, Understanding, and Appreciation for Diverse Users. ACM Trans. Access. Comput. 8, 4, Article 13 (March 2016), 26 pages. https://doi.org/10.1145/2831424

[91] Arlind Reuter, Thomas Scharf, and Jan Smeddinck. 2021. Content Creation in Later Life: Reconsidering Older Adults' Digital Participation and Inclusion. Proceedings of the ACM on Human-Computer Interaction 4, CSCW3 (2021), 1-23.

[92] Eugenia Ha Rim Rho and Melissa Mazmanian. 2019. Hashtag Burnout? A Control Experiment Investigating How Political Hashtags Shape Reactions to News Content. Proceedings of the ACM on Human-Computer Interaction 3 , CSCW (2019), 1-25.

[93] Hannah J Roberts and James M Noble. 2015. Education Research: Changing medical student perceptions of dementia: An arts-centered experience. Neurology 85, 8 (2015), 739-741. 
[94] Julie M Robillard, Thomas W Johnson, Craig Hennessey, B Lynn Beattie, and Judy Illes. 2013. Aging 2.0: health information about dementia on Twitter. PLoS One 8, 7 (2013), e69861.

[95] Dianis Wulan Sari, Ayumi Igarashi, Manami Takaoka, Reiko Yamahana, Maiko Noguchi-Watanabe, Chie Teramoto, and Noriko Yamamoto-Mitani. 2020. Virtual reality program to develop dementia-friendly communities in Japan. Australasian fournal on Ageing (2020).

[96] Morgan Klaus Scheuerman, Stacy M Branham, and Foad Hamidi. 2018. Safe spaces and safe places: Unpacking technology-mediated experiences of safety and harm with transgender people. Proceedings of the ACM on HumanComputer Interaction 2, CSCW (2018), 1-27.

[97] Kristen Shinohara, Saba Kawas, Andrew J. Ko, and Richard E. Ladner. 2018. Who Teaches Accessibility? A Survey of U.S. Computing Faculty. In Proceedings of the 49th ACM Technical Symposium on Computer Science Education (Baltimore, Maryland, USA) (SIGCSE '18). Association for Computing Machinery, New York, NY, USA, 197-202. https://doi.org/10.1145/3159450.3159484

[98] Kristen Shinohara and Jacob O. Wobbrock. 2016. Self-Conscious or Self-Confident? A Diary Study Conceptualizing the Social Accessibility of Assistive Technology. ACM Trans. Access. Comput. 8, 2, Article 5 (Jan. 2016), 31 pages. https://doi.org/10.1145/2827857

[99] Rachel A. Sluis, Daniel Angus, Janet Wiles, Andrew Back, Tingting (Amy) Gibson, Jacki Liddle, Peter Worthy, David Copland, and Anthony J Angwin. 2020. An Automated Approach to Examining Pausing in the Speech of People With Dementia. American fournal of Alzheimer's Disease \& Other Dementiasr 35 (2020), 1533317520939773. https://doi.org/10.1177/1533317520939773 arXiv:https://doi.org/10.1177/1533317520939773 PMID: 32648470.

[100] S Shyam Sundar. 2000. Multimedia effects on processing and perception of online news: A study of picture, audio, and video downloads. fournalism \& Mass Communication Quarterly 77, 3 (2000), 480-499.

[101] S Shyam Sundar. 2008. The MAIN model: A heuristic approach to understanding technology effects on credibility. MacArthur Foundation Digital Media and Learning Initiative.

[102] Kate Swaffer. 2015. Dementia and Prescribed Disengagement ${ }^{\mathrm{TM}}$. Dementia 14, 1 (2015), 3-6. https://doi.org/10.1177/ 1471301214548136 arXiv:https://doi.org/10.1177/1471301214548136 PMID: 25503628.

[103] Catherine V Talbot, Siobhan T O’Dwyer, Linda Clare, Janet Heaton, and Joel Anderson. 2020. How people with dementia use twitter: A qualitative analysis. Computers in Human Behavior 102 (2020), 112-119.

[104] Stephen M Utych and Luke Fowler. 2020. Age-based messaging strategies for communication about COVID-19. fournal of Behavioral Public Administration 3, 1 (2020). https://doi.org/10.30636/jbpa.31.151

[105] Brandon Van Der Heide and Young-shin Lim. 2016. On the conditional cueing of credibility heuristics: The case of online influence. Communication Research 43, 5 (2016), 672-693.

[106] Baldwin Van Gorp and Tom Vercruysse. 2012. Frames and counter-frames giving meaning to dementia: A framing analysis of media content. Social science \& medicine 74, 8 (2012), 1274-1281.

[107] John Vines, Gary Pritchard, Peter Wright, Patrick Olivier, and Katie Brittain. 2015. An age-old problem: Examining the discourses of ageing in HCI and strategies for future research. ACM Transactions on Computer-Human Interaction (TOCHI) 22, 1 (2015), 1-27.

[108] Lisa S Wagner and Tana M Luger. 2017. Assessing positive attitudes toward older and younger adults. Educational Gerontology 43, 3 (2017), 147-165.

[109] Jayne Wallace, Peter C. Wright, John McCarthy, David Philip Green, James Thomas, and Patrick Olivier. 2013. A Design-Led Inquiry into Personhood in Dementia. In Proceedings of the SIGCHI Conference on Human Factors in Computing Systems (Paris, France) (CHI '13). Association for Computing Machinery, New York, NY, USA, 2617-2626. https://doi.org/10.1145/2470654.2481363

[110] Nathan Walter, Sheila T Murphy, Lauren B Frank, and Lourdes Baezconde-Garbanati. 2017. Each medium tells a different story: the effect of message channel on narrative persuasion. Communication Research Reports 34, 2 (2017), 161-170.

[111] Joseph B Walther. 1996. Computer-mediated communication: Impersonal, interpersonal, and hyperpersonal interaction. Communication research 23, 1 (1996), 3-43.

[112] Joseph B Walther. 2011. Theories of computer-mediated communication and interpersonal relations. The handbook of interpersonal communication 4 (2011), 443-479.

[113] Peter Samuelson Wardrip, R Benjamin Shapiro, Andrea Forte, Spiro Maroulis, Karen Brennan, and Ricarose Roque. 2013. CSCW and education: viewing education as a site of work practice. In Proceedings of the 2013 conference on Computer supported cooperative work companion. 333-336.

[114] Jenny Waycott, Frank Vetere, Sonja Pedell, Lars Kulik, Elizabeth Ozanne, Alan Gruner, and John Downs. 2013. Older adults as digital content producers. In Proceedings of the SIGCHI conference on Human Factors in Computing Systems. 39-48.

[115] Daniel Welsh, Kellie Morrissey, Sarah Foley, Roisin McNaney, Christos Salis, John McCarthy, and John Vines. 2018. Ticket to talk: Supporting conversation between young people and people with dementia through digital media. In 
proceedings of the $2018 \mathrm{CHI}$ conference on human factors in computing systems. 1-14.

[116] Perla Werner. 2005. Social distance towards a person with Alzheimer's disease. International fournal of Geriatric Psychiatry: A journal of the psychiatry of late life and allied sciences 20, 2 (2005), 182-188.

[117] Dmitri Williams, Scott Caplan, and Li Xiong. 2007. Can you hear me now? The impact of voice in an online gaming community. Human communication research 33, 4 (2007), 427-449.

[118] Matthew Williams and Stephanie Daley. 2020. INNOVATION IN DEMENTIA EDUCATION WITHIN UNDERGRADUATE HEALTHCARE PROGRAMMES: A SCOPING REVIEW. Nurse Education Today (2020), 104742.

[119] Jacob O. Wobbrock, Leah Findlater, Darren Gergle, and James J. Higgins. 2011. The Aligned Rank Transform for Nonparametric Factorial Analyses Using Only Anova Procedures. In Proceedings of the SIGCHI Conference on Human Factors in Computing Systems (Vancouver, BC, Canada) (CHI '11). Association for Computing Machinery, New York, NY, USA, 143-146. https://doi.org/10.1145/1978942.1978963

[120] Crystal D Wotipka and Andrew C High. 2016. An idealized self or the real me? Predicting attraction to online dating profiles using selective self-presentation and warranting. Communication Monographs 83, 3 (2016), 281-302.

[121] Takashi Yamashita, Jennifer M Kinney, and Elizabeth J Lokon. 2013. The impact of a gerontology course and a service-learning program on college students' attitudes toward people with dementia. fournal of Applied Gerontology 32, 2 (2013), 139-163.

Received October 2021; revised April 2021; accepted July 2021 